\title{
Causal effects on employment after first birth - A dynamic treatment approach -
}

Citation for published version (APA):

Fitzenberger, B., Sommerfeld, K., \& Steffes, S. (2013). Causal effects on employment after first birth - A dynamic treatment approach -. ROA. ROA Research Memoranda No. 010

https://doi.org/10.26481/umaror.2013010

Document status and date:

Published: 01/01/2013

DOI:

10.26481/umaror.2013010

Document Version:

Publisher's PDF, also known as Version of record

\section{Please check the document version of this publication:}

- A submitted manuscript is the version of the article upon submission and before peer-review. There can be important differences between the submitted version and the official published version of record.

People interested in the research are advised to contact the author for the final version of the publication, or visit the DOI to the publisher's website.

- The final author version and the galley proof are versions of the publication after peer review.

- The final published version features the final layout of the paper including the volume, issue and page numbers.

Link to publication

\footnotetext{
General rights rights.

- You may freely distribute the URL identifying the publication in the public portal. please follow below link for the End User Agreement:

www.umlib.nl/taverne-license

Take down policy

If you believe that this document breaches copyright please contact us at:

repository@maastrichtuniversity.nl

providing details and we will investigate your claim.
}

Copyright and moral rights for the publications made accessible in the public portal are retained by the authors and/or other copyright owners and it is a condition of accessing publications that users recognise and abide by the legal requirements associated with these

- Users may download and print one copy of any publication from the public portal for the purpose of private study or research.

- You may not further distribute the material or use it for any profit-making activity or commercial gain

If the publication is distributed under the terms of Article $25 \mathrm{fa}$ of the Dutch Copyright Act, indicated by the "Taverne" license above, 
Maastricht University

Research Centre for Education and the Labour Market | ROA

Causal effects on employment after first birth - A dynamic treatment approch -

Bernd Fitzenberger

Katrin Sommerfeld

Susanne Steffes

\section{ROA Research Memorandum}

ROA-RM-2013/10

Research Centre for Education and the Labour Market Maastricht University

P.O. Box 616, 6200 MD Maastricht, The Netherlands

$\mathrm{T}+31433883647 \mathrm{~F}+31433884914$

secretary-roa-sbe@maastrichtuniversity.n www.roa.nl 


\title{
Causal effects on employment after first birth - A dynamic treatment approach -
}

\author{
Bernd Fitzenberger \\ Katrin Sommerfeld \\ Susanne Steffes
}

ROA-RM-2013/10*

June 2013

Research Centre for Education and the Labour Market

Maastricht University

P.O. Box 616, 6200 MD Maastricht, The Netherlands

$\mathrm{T}+31433883647 \mathrm{~F}+31433884914$

secretary-roa-sbe@maastrichtuniversity.nl

www.roa.nl

\footnotetext{
* The ROA Research Memorandum Series was created in order to make research results available for discussion, before those results are submitted for publication in journals.
} 


\section{Abstract}

\section{Causal effects on employment after first birth - A dynamic treatment approach - **}

The effects of childbirth on future labor market outcomes are a key issue for policy discussion. This paper implements a dynamic treatment approach to estimate the effect of having the first child now versus later on future employment for the case of Germany, a country with a long maternity leave coverage. Effect heterogeneity is assessed by estimating ex post outcome regressions. Based on SOEP data, we provide estimates at a monthly frequency. The results show that there are very strong negative employment effects after childbirth. Although the employment loss is reduced over the first five years following childbirth, it does not level off to zero. The employment loss is lower for mothers with a university degree. It is especially high for mediumskilled mothers with long prebirth employment experience. We find a significant reduction in the employment loss for more recent childbirths.

JEL classification: C14, J13, J22

Keywords: female labor supply, maternity leave, dynamic treatment effect, inverse probability weighting

Bernd Fitzenberger

University of Freiburg

Institute for Economic Research

Department of Applied Econometrics

79085 Freiburg

Germany

bernd.fitzenberger@vwl.uni-freiburg.de

and IFS, IZA, ROA and ZEW

Susanne Steffes

Centre for European Economic Research

ZEW

P.O. Box 103443

68034 Mannheim

Germany

steffes@zew.de

\author{
Katrin Sommerfeld \\ University of Freiburg \\ Institute for Economic Research \\ Department of Applied Econometrics \\ 79085 Freiburg \\ Germany \\ katrin.sommerfeld@vwl.uni-freiburg.de
}

** We thank Martha Bailey, Annette Bergemann, Hans-Peter Blossfeld, Steffen Künn, Astrid Kunze, Helena Skyt Nielsen and Jeffrey Smith for fruitful discussions. Moreover, we benefitted from comments during seminar presentations at EALE (Bonn), University of Michigan in Ann Arbor, University of York, IZA Summer School, ESPE (Essen), University of Freiburg, SOEP user conference (Berlin), SSES (Fribourg), Workshop on Empirical Analysis of Family Economics (Aarhus), Leopoldina Workshop (Munich), Ausschuss für Ökonometrie, and ZEW Mannheim. 


\section{Contents}

1 Introduction 1

2 Institutional Background $\quad 6$

3 Econometric Approach $\quad 7$

3.1 Dynamic Treatment Approach _ . . . . . . . . . . . . . . . . . 8

3.2 Inverse Probability Weighting (IPW) . . . . . . . . . . . . . 11

3.3 Outcome regression based on IPW . . . . . . . . . . . . . . . 13

4 Data 14

5 Empirical Results $\quad 16$

5.1 Descriptive Statistics before and after IPW-matching . . . . . . . . . 16

5.2 Average Treatment Effect on the Treated (ATT) . . . . . . . . . . 18

5.3 Time Trend and 2001 Reform . . . . . . . . . . . . . . . . 23

5.4 Sensitivity Analysis . . . . . . . . . . . . . . . . . 24

6 Conclusions $\quad 26$

$\begin{array}{lr}\text { References } & 28\end{array}$

$\begin{array}{ll}\text { Appendix } & 32\end{array}$ 


\section{Introduction}

Reconciling work and family life is a key issue in recent policy debates (OECD, 2007). Childbirth is associated with a strong reduction in female employment right after birth, which in a life-cycle perspective has adverse effects on later labor market outcomes (OECD, 2002; Ondrich et al., 1999; Schönberg and Ludsteck, 2012). Decisions about career objectives and about starting a family have to be taken jointly - usually between the age of 20 and 40 years. Many Western countries exhibit a combination of low fertility rates and low female labor market participation rates, which poses great challenges for future economic development. There has been a lively discussion as to whether mothers in the U.S. increasingly "opt-out" of the labor market, although there is no clear evidence for such a trend (Goldin, 2006; Fortin, 2009). Empirical estimates of the effects of motherhood on subsequent employment have to address the selection into motherhood. Our paper contributes to this literature, first, by suggesting and implementing a dynamic treatment approach to estimate the effect of having the first child now versus later on future employment. Second, we study the case of Germany, a country with a long maternity leave coverage (Schönberg and Ludsteck, 2012).

A large literature estimates the causal effects of birth on subsequent employment of mothers by means of different identification strategies. Earlier quasi-experimental studies for the U.S. estimate the labor supply effects in response to an increase in the number of children (Bronars and Grogger, 1994; Angrist and Evans, 1998). ${ }^{1}$ In a more recent study, Cristia (2008) estimates the effect of a first child exploiting the quasi-experimental variation in fertility among women who seek help to become pregnant. There also exists a large literature on the negative effects of having children on mothers' wages. Waldfogel (1998a,1998b) identifies as the main reason for large wage losses the long employment breaks after childbirth associated with employer changes. For the UK, Millimet (2000) estimates a causal effect with a simultaneous model using a covariance restriction as identifying strategy. Ejrnaes and Kunze (2012) and Schönberg and Ludsteck (2012) use German policy reforms to investigate the causal effect of births on female wages in Germany.

In an approach, which is more closely related to our study, Simonsen and Skipper (2006) match nonparametrically mothers and non-mothers for Denmark based on observable exogenous covariates based on register data. The study estimates the wage costs of motherhood. The authors account for the effects of motherhood on some observable characteristics and distinguish between the direct effect holding these characteristics constant

\footnotetext{
${ }^{1}$ Bronars and Grogger (1994) use the fact of having twins in the first birth to instrument having a second child. Angrist and Evans (1998) exploit the preference for mixed-sex siblings in order to estimate the preference having more than two children.
} 
and the indirect effects operating through the changes in these characteristics. Most of the wage costs of motherhood are found to operate through the indirect effects.

While the aforementioned studies provide evidence on the negative effect of childbirth versus not having a child on subsequent labor market outcomes, these studies do not address the question of timing of birth. Given that a large share of women is giving birth to a child at some point in their lives and that women are taking important career decisions at the same time in life, various studies in the literature analyze the timing of childbirth. Miller (2011), Wilde et al. (2010), and Troske and Voicu (2010, 2012) investigate the effects of timing of first birth on labor supply and wages of mothers in the U.S.. Although different estimation methods and identification strategies are applied, our paper is closely related to this literature.

Troske and Voicu $(2011,2012)$ use a complex semi-structural five-equation model to analyze the effect of timing and spacing of births on employment by estimating a multinomial probit model for different employment states (full time, part time, etc) and, simultaneously, a probit model for the fertility decision. The advantage of this approach is the simultaneous modeling of labor supply and fertility decisions. Identification is mainly driven by including the number of children of the mother's siblings. However, this identification strategy requires a tight specification of the timing of the decision process. Furthermore, the empirical analysis is restricted to the selective sample of married women who have a first child after marriage. The estimated model contrasts the employment outcome of mothers with the employment outcome of childless women. Troske and Voicu (2012) find that delaying the first birth leads to higher levels of labor market involvement before the birth of the first child and reduces the negative employment effects after birth. Troske and Voicu (2010) emphasize the strong persistence of labor market states, therefore enhancing the lasting negative effects of childbirth on employment. The study also finds strong effect heterogeneity of birth with respect to observables and unobservables.

Miller (2011) and Wilde et al. (2010) estimate the effect of higher age at first birth on subsequent labor market outcomes, using women who have a child at a later age as the control group for women who have a child at an earlier age (see also Herr $(2009,2011)$ for related studies). Miller (2011) instruments age at first birth by naturally occuring fertility shocks. The study finds that delaying first birth increases employment and wages after birth. The effects are strongest for women with a college degree and for those in professional and managerial occupations. Wilde et al. (2010) criticize the instruments used by the former study, especially with regard to the lack of exogeneity in case of timevarying instruments and to measurement error problems. Instead, they use characteristics of parents or events having occured at an early age to instrument the age at first birth. 
The study also finds that delaying first birth improves earnings after birth. Wilde et al. (2010) and Miller (2011) explore how the wage and career consequences of motherhood differ by skill and timing. Wage trajectories diverge sharply for high-skilled women after they have children (but not before), while there is little change for low-skilled women. The higher career costs of childbirth may account for the greater tendency of high-skilled women to delay birth or to avoid having a child altogether. Correspondingly, Miller (2011) finds that delaying birth shows a stronger positive effect for high-skilled women compared to less-skilled women.

Why is the case of Germany interesting? As in many countries, the political debate in Germany focuses on the joint nature of fertility and employment decisions. In light of the long maternity leave coverage of 36 months of job-protected leave, there has been growing concern that mothers do not return to their job and that their careers are actually negatively affected by such long employment interruptions. Over time, social norms seem to have changed, now favoring employment of mothers with young children, and policy changes to allow for a reconciliation of employment and family tasks are asked for. Firms take efforts to balance work and family roles, fathers have increased their involvement in informal childcare, and the availability of formal childcare for children below the age of three has increased strongly. Policy makers implemented a policy reform in 2001 providing financial incentives for an earlier return-to-job after childbirth and fostering part time work when the child is still young. Another reform was implemented in 2007 with the intent to foster female labor supply as well as fertility.

Until now little is known about the magnitude of longitudinal employment losses after first childbirth in Germany and their changes over a longer time period accounting for differences by age and skill group. Most of the existing studies for Germany analyze the impact of policy changes in maternity leave coverage. ${ }^{2}$ Ondrich et al. $(1996,2003)$ and Schönberg and Ludsteck (2012) find that increases of the maximum duration of maternity leave between 1986 and 1992 led to a successive rise in the duration of employment interruptions. ${ }^{3}$ Bergemann and Riphahn (2011) and Kluve and Tamm (2012) find that the 2007 reform which increased considerably the income support for the first year of parental leave, while cutting it for the second and third year led to a shift in the employment patterns of mothers during the first three years after birth. During the first 12 months the employment rates decline, while after 12 months the employment rates increase. Kluve and Tamm (2012) and Schönberg and Ludsteck (2012) estimate causal effects by applying a

\footnotetext{
${ }^{2}$ Strictly speaking, Germany provides parantal leave coverage. However, until the mid 2000s parental leave is typically taken by female workers.

${ }^{3} \mathrm{~A}$ similar result is found by Lalive and Zweimüller (2009) for Austria and by Baker and Milligan (2008) for Canada.
} 
regression discontinuity design. The advantage of this approach is the random assignment of the treatment, as couples can hardly plan the exact timing of birth and did not know about the reform at the time of conception. However, one may be concerned about the external validity of these results in light of the possibility that individuals adjust their behavior over time when an institutional change is associated with changes in social norms (see Fortin, 2009, for the importance of gender role attitudes).

As the opportunity costs of childbirth vary with acquired human capital, e.g. higher work experience or education, the timing of first birth has an important impact on future career outcomes (Miller, 2011; Wilde et al., 2010; Troske and Voicu, 2009). Put differently, women of a certain age decide whether to have a child now or wait - with the expected negative career effects varying by age. This raises two questions to be addressed by our study: 1) Does the timing of first birth have an impact on post-birth employment in Germany? 2) Is this impact in line with human capital theory, i.e. is the negative treatment effect weaker for women with more human capital? Our analysis recognizes that postbirth employment behavior affects future employment chances since longer breaks and lower working hours reduce the amount of human capital (Lefebvre et al., 2009; Beblo and Wolf, 2002). Clearly, the employment behavior in the first years after childbirth depends on the private environment, institutions (for instance availability of childcare, see Kreyenfeld and Hank, 2000; van Ham and Büchel, 2004), but also on pre-birth employment and education. Furthermore, the fertility decision is based on the expected employment chances after childbirth. On the one hand, women with higher human capital or higher labor force attachment have the most to lose from an employment break in terms of human capital and, thus, career opportunities (Troske and Voicu, 2009; Miller, 2011). We would therefore expect older and more educated first-time mothers to catch up more quickly to the control group than younger or less educated first-time mothers. On the other hand, older first-time mothers may have had a successful career already, which might increase the employment loss caused by the birth of a first child. Thus, the direction of how the employment effect of first childbirth among the women having a first child varies with age is an empirical question.

Out paper implements a dynamic treatment effect approach, which does not require a complete modelling of the fertility and labor market decisions. We estimate the causal effect of first childbirth on female employment over the course of five years after birth. Our empirical analysis uses data on first childbirth between the age of 24 and 33 from the GSOEP for the time period 1991 to 2008, as the GSOEP provides not only detailed monthly information on employment, but also a large set of control variables (including information on the partner and on attitudes towards family). 
Our estimation approach has been used before to estimate the effect of active labor market policies (Sianesi, 2004, 2008; Fitzenberger et al., 2013) in a situation, where nontreated individuals today may be treated in the future. This approach also draws on Fredriksson and Johansson (2008) and Lechner (2009), and is linked to the timingof-events approach of Abbring and van den Berg (2003). We address the selection into childbirth by contrasting first-time mothers with highly comparable women who display a similar propensity to have a first child soon. This comparison is based on reduced-form estimates of the propensity to have a first child at a certain time and age. We assume that individuals decide whether to have a child now or wait. After conditioning on labor market history and personal characteristics, the exact timing of birth is assumed random, which is the basis of our identification strategy. We cannot estimate the causal effect of having a child versus never having a child or of having a child at a higher age versus at a lower age (delay childbirth). Conditioning on not giving birth in the future or conditioning on given birth in the future at a certain age would result in a highly selective control group. The literature addresses this problem by using quasi-experimental variation in the data or by fully modelling the selection on unobservables. Instead, our approach allows control individuals to either have a child later or to never have a child. We align treated and control individuals dynamically by age, and we match treated and controls using inverse probability weighting (IPW) with weights normalized to sum up to one (Busso et al., 2009). Finally, we employ ex-post outcome regressions (Abadie and Imbens, 2011) to analyze the heterogeneity of the estimated employment effects. Note that, in contrast to most of the literature discussed for Germany, we do not use a policy reform as exogenous variation to identify the causal effect of childbirth on employment. However, we investigate to what extent the estimated effect changes over time, possibly in response to changing social norms towards employment of mothers.

Our results show a sharp decline in employment around childbirth. The average treatment effect on the treated slowly converges to zero, implying that employment rates recover as the child grows older. However, we also show that within the observation period of five years, the estimated average treatment effects on the treated do not level off. As expected from human capital theory, the employment loss is lower for mothers with a university degree. It is especially high for medium-skilled mothers with long pre-birth employment experience. We find a significant reduction in the employment loss for more recent childbirths.

The paper proceeds as follows. The institutional background in Germany is described in section 2. Section 3 develops the econometric approach and section 4 describes the data used. The empirical results are discussed in section 5. Section 6 concludes. 


\section{Institutional Background}

Maternity leave coverage in Germany, which provides employment protection after childbirth, was extended to three years in the early 1990s, which is very generous in international comparison (OECD, 2002; Schönberg and Ludsteck, 2012). However, there is concern that the long maternity leave coverage is one of the reasons for the low employment rates of German mothers (OECD, 2002; Schönberg and Ludsteck, 2012; Ondrich et al., 1999). As a result, the German government changed the rules that regulate income support during maternity leave in 2001 and in 2007 in order to increase the incentive for mothers to return to their jobs sooner. ${ }^{4}$

Two different laws govern maternity leave coverage (Kreyenfeld, 2001; Schönberg and Ludsteck, 2012), both of which concern the job protection and the regulation of financial benefits, but apply to different time periods. The "Maternity Protection Law" (Mutterschutzgesetz) requires a pregnant woman to temporarily stop working six weeks before and eight weeks after birth in order to protect her and the baby's health. ${ }^{5}$ During this period, the mother receives her full net labor income which is financed partly by the employer and partly by the health insurance.

The "Parental Leave Law" (Elternzeitgesetz) regulates the job protection period and the income assistance during the parental leave period. ${ }^{6}$ The job protection involves the right to return to a comparable job at the previous employer, but this does not necessarily have to be exactly at the same workplace as before birth. The job protection period is three years of which up to twelve months may be delayed until the child reaches the age of eight. Effects of the extensions of maternity leave coverage from the 1970s to the early 1990s on children outcomes are analyzed by Dustmann and Schönberg (2012). According to the "Parental Leave Law", parental benefits are paid only if the parent on leave does not work

\footnotetext{
${ }^{4}$ The 2007 reform has received more attention in the public debate compared to the 2001 reform. In particular, the income support was changed from a means-tested flat transfer to a transfer which is proportional to the earnings before birth (up to a maximum level of Euro 1800) during the first year after birth. After 2007, all employed mothers are eligible for this new transfer and the level of the transfer is much higher. At the same time, the transfer was limited to a time period of 12 months. The 2007 reform also stipulates that the period with income support can be extended to 14 months if both parents take at least 2 months of maternity leave. Two goals of the reform were to (i) increase the incentives for employed fathers to take part of the maternity leave and to share the child care with the mother and (ii) help women to combine work and family and therefore allow for a quicker return to the job after birth.

${ }^{5}$ The post-birth break is mandatory whereas for the pre-birth period, women can apply for an exemption. In the case of giving birth to twins the after-birth period is extended to twelve weeks.

${ }^{6}$ Parents can share paternity leave coverage and the cumulated leave periods can amount to at most three years. Thus, the maximum leave period for fathers is three years minus maternity protection after birth.
} 
more than the allowed amount of hours, lives in the same household and predominantly cares for the child by him- or herself. Before 2001, a parent on parental leave had been allowed to work at most 19 hours a week. In January 2001, this upper bound was extended to 30 hours. In addition, the parent on leave - if eligible- was given the right to choose between receiving 300 Euro per month during the first 24 months or 450 Euro per month during the first 12 months. This should provide incentives for a return-to-job after 12 or 24 months. The maternity benefit was means-tested, i.e. it was paid to families with an annual net income less than 30,000 Euro in two-parent households and 23,000 Euro in single-parent households. Six months after birth these boundaries decreased to 16,500 $(13,500)$ Euro plus 3,140 Euro for each additional child. Furthermore, families receive a monthly child allowance (Kindergeld) for dependent children of today 184 Euro for the first and second child, 190 Euro for the third child and 215 Euro for all further children. Table 1 shows the development of the child allowance during our observation period. As an alternative, families can choose a tax exemption for dependent children, which is more attractive for high income families. Moreover, at exactly the same date as the reform discussed so far (January 2001), there was another political reform which facilitated part time work, regardless of having children or not. The latter reform established a legal claim for part time work and regulated fixed term contracts ("Teilzeit- und Befristungsgesetz").

\section{[ Table 1 about here. ]}

Working mothers also need formal or informal childcare for their children. In 2007, around 14 percent of all children under the age of three attended formal or institutional childcare (Mühler, 2010). The coverage is 37 percent in East Germany and only 8 percent in West Germany. In West Germany, the availability of formal childcare for children under the age of three has been growing slowly over time, starting from a very low level. From age three on, every child in Germany is entitled to formal institutional childcare in kindergarten. For this age group, the attendance rate amounts to 89 percent. However, the opening hours in most of the existing childcare facilities are often not sufficient (Boll, 2009) and attendance is often only on a part time basis. The lack of suitable formal childcare is often viewed as an obstacle for higher employment levels among mothers of young children in Germany.

\section{Econometric Approach}

Our goal is to estimate the average treatment effect for the treated (ATT) on employment based on discrete time data. The treatment is 'first childbirth at a certain age' against 
the alternative of waiting. The alternative of waiting, i.e. of not having a first childbirth now, entails both the possibility of never having a child and the possibility of having a child at a later age. This treatment effect has been suggested by Sianesi $(2004,2008)$ in the context of estimating the effects of active labor market programs. Note that we do not estimate the treatment of having a first child now versus never having a child in life.

We assume a dynamic conditional independence assumption (a sequential randomization assumption) and apply inverse probability weighting (IPW) based on the estimated propensity score (Hirano et al., 2003; Lechner, 2009). Following Busso et al. (2009), we implement the IPW estimator for the ATT by normalizing the weights of the members in the comparison group to sum up to one. Because our control group changes by age at first birth and since there is attrition in the control group over time, the normalization of weights changes along the two dimensions 'age at first birth' and 'elapsed time since birth'. We summarize the ATT estimates and analyze effect heterogeneity using weighted outcome regressions as suggested by Abadie and Imbens (2011) for matching estimators. The next subsection introduces and motivates the treatment parameter to be estimated (section 3.1). Section 3.2 then describes our implementation of the IPW estimator. Finally, we introduce the weighted outcome regression based on IPW (section $3.3)$.

\subsection{Dynamic Treatment Approach}

The treatment effect that we estimate is the effect of treatment versus waiting, as introduced by Sianesi $(2004,2008)$. Thus, for a certain age, we estimate the ATT of having a first child at this age versus not having a child at this age. The group of nontreated women consists both of women who never have a child and who have a child at a later age. This definition of the control group avoids conditioning on future outcomes. Treated and nontreated women at a certain age did not have a child before the considered age. Furthermore, we match treated and nontreated women by observable characteristics twelve months before birth.

The treatment effect we estimate is an example for the dynamic treatment approach applied in the context of program evaluation of active labor market policies by Sianesi (2004, 2008) for Sweden or by Fitzenberger et al. (2013) for Germany. These countries have a comprehensive system of active labor market policies implying that with some probability, unemployed individuals who have not been treated by a certain point of time may receive treatment later. If one constructs a control group based on individuals who are not treated during the observation window, one runs the risk of conditioning on future outcomes as, for example, individuals will not participate in treatment in the future if they 
have found a job before. Put differently, individuals who are eligible for treatment at a certain point of time but receive treatment later would be excluded from the control group. The exit from unemployment to employment and the entry into program participation are two competing risks, and unobserved characteristics are typically correlated with the chances of finding a job (quickly) as well as with program participation. Correspondingly, Sianesi (2004, 2008) and Fredriksson and Johansson (2008) argue that excluding future participants from the control group would lead to biased estimates of the treatment effect due to selection on unobservables.

The key identification assumption for our analyis is a dynamic conditional independence assumption (a sequential randomization assumption) stating that conditional on the variables controlled for until a certain time period the assignment to treatment in this time period is random, i.e. independent of the potential outcomes. To estimate the ATT, it suffices to assume conditional independence of assignment with the potential non-treatment outcome. A key threat to identification would be the anticipation of actual treatment in the future, which would entail the risk of conditioning on future treatment by conditioning on past outcomes.

Our application of the dynamic treatment approach is comparable to the training literature example insofar as the control group remains childless up to the considered point in time (similar to unemployed individuals remaining jobless and/or without training). This highlights the importance of avoiding conditioning on future outcomes. Therefore, in our application, for women giving birth for the first time at a certain age, we do not exclude the alternative of giving first birth at a later age. This corresponds to the dynamic nature of fertility decisions, which are taken jointly with career decisions. As Ciliberto et al. (2012, p. 10) put it "[...] employees make their fertility choices many times in their lives [...]". Using solely a control group of women who do not give first birth until a much later age or who will never have a child would bias the control group towards women with a low propensity of having a child. This is due to selection into motherhood. ${ }^{7}$ This bias is likely to be correlated with labor market outcomes (e.g. women with a strong unobserved career orientation are more likely to exhibit a higher labor market attachment and lower fertility rates). ${ }^{8}$ The endogeneity problem of fertility and employment also arises due to potential labor market shocks and shocks related to personal circumstances (relationships,

\footnotetext{
${ }^{7} \mathrm{~A}$ number of studies use non-mothers for comparison and this way include selection into motherhood in the estimated effect (Ejrnaes and Kunze, 2012; Fernandez-Kranz et al., 2013; Simonsen and Skipper, $2006)$.

${ }^{8}$ The underlying reason for this type of endogeneity is that both fertility and career are controlled by women (at least in part, see Troske and Voicu, 2010). For different approaches to address endogeneity in this context, see Miller (2011), Herr (2009, 2011), Gustafsson et al. (1996), and Wilde et al. (2010).
} 
household characteristics), with differential effects on fertility and labor market outcomes. It is plausible that positive labor market shocks are negatively correlated with future fertility or that personal shocks, which reduce the fertility in the future, are also correlated with labor market outcomes. ${ }^{9}$ For the purpose of our analysis, these effects are similar in nature to the competing risks approach prevalent in the timing-of-events analysis of active labor market policies. Therefore, the results would be biased if we excluded women who give first birth later (Wilde et al., 2010). This argument assumes that we cannot control unobserved heterogeneity of the treated women if we merely consider nontreated women who do not give birth in the future. Instead we follow Sianesi $(2004,2008)$ and assume that women giving birth to their first child are comparable before the gestation lag, i.e. at the time before pregnancy, to women who do not give birth at a certain point in time, i.e. at a certain age. This approach assumes that women do not know the exact timing of first birth before the gestation period. But they may know the probability of having a first birth now versus later and they may act upon the determinants of this probability (Abbring and van den Berg, 2003). Assuming a no-anticipation condition with respect to the precise date of pregnancy before the gestation period allows us to match treated and nontreated women at this date.

The treatment group in our analysis consists of women who have their first child between the age of 24 and 33 and who are not retired or disabled. The control group consists of women who did not have a child at the age of the treated mother at the time of birth. ${ }^{10}$ Hence, we assign to each treated woman an individual-specific control group, thereby imposing an exact alignment of the age in months. We measure both the treatment effect and the age of the women at a monthly frequency. For the purpose of presenting our results, we pool the month-specific treatment effects into groups (see section 5). For example, there should be little difference between a women who has her first child at 26 years and 11 months or at exactly 27 years. Our analysis estimates an average counterfactual outcome for each treated woman based on the individual-specific group of individuals not treated yet.

We assume that the rich set of covariates allows us to capture systematic differences in the propensity to have a first child at a certain age. Specifically, we assume that given the duration of childlessness and given the covariates, having a first birth within the next year is random, i.e. the dynamic conditional independence assumption holds (DCIA as discussed in Fitzenberger et al., 2013). This randomness in the exact month of birth is

\footnotetext{
${ }^{9}$ An extreme example may be a work accident of a woman which prevents her both from working and from having a child in the future.

${ }^{10}$ We impose that the control women remain childless for at least three months after the respective age month of birth, and we also investigate the sensitivity of the results to doing so.
} 
given by nature, as "conceptions are not perfectly controllable events" (Hotz and Miller, 1988, p. 91). Furthermore, we assume that the timing within the year considered, i.e. the month of birth, is unrelated to the selection into first birth.

The DCIA can be motivated as follows for the age range considered. Our data allow to control for a large number of characteristics regarding education, labor market experience, relationships, and attitudes. Note that our data are particularly rich in this regard compared to administrative data used in the literature (Simonsen and Skipper, 2006; Ejrnaes and Kunze, 2012), thus making the DCIA particularly plausible in our application. One year before birth, the treated women are not likely to differ systematically from those women who stay childless at least for 15 more months. The exact timing of birth cannot be planned with certainty and may depend upon random circumstances not reflected in long-run labor market choices. It is rather implausible that women plan the exact month of first birth more than a year ahead. ${ }^{11}$ At the same time, women differ in their probability to have a child within the next year and this is likely to be reflected by the characteristics that are being controlled for. Thus, controlling for these variables hopefully makes women comparable in the probability to have a child. We argue that the DCIA is particularly plausible during the age range of 24 to 33 years. Concerning the lower bound, at age 24 , women have realized the major parts of their human capital investments and most of them have started their labor market career. As for the upper bound, in their late 30s it is likely that first time mothers and childless women become less comparable. Because the fecundity starts to drop in the 30s and giving birth becomes more risky at a higher age, most women in their late 30s may either be determined to have a child or decide to stay childless (i.e. the probability to have a child is close to zero). ${ }^{12}$ Thus, treated and non-treated females are likely to become less comparable at a higher age because many of them may act upon the anticipation as to whether and when they will have a child.

\subsection{Inverse Probability Weighting (IPW)}

To control the selection of treated women, we estimate a sequence of quarterly propensity scores. ${ }^{13}$ The probability of having the first child within the next year is modeled as

\footnotetext{
${ }^{11}$ Cristia (2008) provides a detailed and informative discussion of the inherent randomness in becoming pregnant even when the women intends to have a child.

${ }^{12}$ Based on U.S. data, Miller (2011) argues that the decline of fecundity with age is highly nonlinear, and is apparent primarily for pregnancies after age 33. Analogous to Miller (2011), we only consider first childbirths up to the mother's age of 33. For empirical descriptions of the fertility decline with age, see e.g. Stein, 1985, p. 328 and Imthurna et al., 2008, p. 126.

${ }^{13}$ The size of the treatment sample is not sufficient to go down to a monthly frequency when estimating the propensity scores. Furthermore, we think that the selection into childbirth does not change strongly
} 
a function of human capital and employment history, which is particularly important if decisions on having a child and decisions on the labor market career are taken jointly. As sequential labor market decisions are correlated (Troske and Voicu, 2010), controlling for past labor market career is crucial for successful matching. Moreover, we control for status of the relationship with the partner and for the self reported importance of having a family. ${ }^{14}$ We include covariates of the partner, such as income and education, to try to proxy for the partner's role in the joint decision process.

Under the unconfoundedness of the treatment and perfect overlap in the propensity score, Busso et al. (2009) conclude that in small samples with unknown propensity score, a modified inverse probability weighting estimator (IPW) performs best in comparison to various matching estimators. This result stands in contrast to the conclusions obtained by the Monte Carlo study in Frölich (2004). The crucial modification of the IPW estimator involves the normalization of weights for the nontreated women. According to the results of Busso et al. (2009), the poor performance of IPW reported by Frölich's (2004) Monte Carlo study is due to the fact that Frölich does not normalize the IPW weights. Doing so strongly improves the performance of the estimator as found by Busso et al. (2009), who suggest to estimate the ATT as follows (Busso et al., 2009, eq. (7)):

$$
\hat{\theta}_{B D M}=\frac{\sum_{i=1}^{n} T_{i} Y_{i}}{\sum_{i=1}^{n} T_{i}}-\frac{\sum_{j=1}^{n}\left(1-T_{j}\right) \hat{W}_{j} Y_{j}}{\sum_{j=1}^{n}\left(1-T_{j}\right) \hat{W}_{j}}
$$

with weights $\hat{W}_{j}=\hat{p}\left(X_{j}\right) /\left(1-\hat{p}\left(X_{j}\right)\right)$.

Furthermore, $T_{i}, T_{j}$ denote the treatment dummy variables for individuals $i, j$ (treated and non-treated), respectively, and $\hat{p}\left(X_{j}\right)$ denotes the estimated propensity score as a function of covariates $X_{j}$. The application of the weights $W_{j}$ leads to a reweighting of the nontreated women according to the odds-ratio of having a child within the next year. Note that the denominator corresponds to the sum of the weights in the numerator.

For our application, we have to account for the fact that for the estimation of treatment versus waiting, the group of eligible comparison women changes by month of age. Correspondingly, the alignment between treated and nontreated observations changes as well by month of age. The higher the age, the smaller the 'eligible' control group for first birth. Thus, we modify the estimator in equation (1) to

$$
\hat{\theta}=\frac{\sum_{i=1}^{n} T_{i}\left\{Y_{i}-\frac{\sum_{j=1}^{n}\left(1-T_{j}\right) \hat{W}_{i, j} Y_{j, a g e(i)}}{\sum_{j=1}^{n}\left(1-T_{j}\right) \hat{W}_{i, j}}\right\}}{\sum_{i=1}^{n} T_{i}}
$$

\footnotetext{
from month to month.
}

${ }^{14}$ In fact, in contrast to matching, the reweighting estimator we will use later requires the propensity score to be a conditional probability (Busso et al., 2009), which is evident in our application. As there seems sufficient overlap, we do not use any trimming, see Figure 3. 
with weights $\hat{W}_{i, j}=E_{i, j} \hat{p}\left(X_{j}\right) /\left(1-\hat{p}\left(X_{j}\right)\right)$.

$E_{i, j}$ is a dummy variable which takes the value of one if woman $j$ can be used as a control observation for treated woman $i$, i.e. if $j$ remains childless for at least three months after the respective age at first birth for the treated woman $i . E_{i, j}$ is set to zero if woman $j$ has a child earlier than the three months after birth for woman $i$. $Y_{j, a g e(i)}$ is the outcome of control woman $j$ aligned to the age at first birth for treated woman $i$.

This IPW or reweighting estimator has the advantage of not relying on a tuning parameter such as a bandwidth in kernel matching or the number of nearest neighbors in nearest neighbor matching. Moreover, it is easy to implement and standard errors are readily obtained by bootstrapping. Busso et al. (2009) show that this estimator is preferred in terms of bias and variance in finite sample settings with unknown propensity score. However, they stress that this only holds with good overlap and when misspecification of the propensity score is not a concern.

\subsection{Outcome regression based on IPW}

In order to account for time trends and to assess effect heterogeneity by observable characteristics (e.g., by age, education, time), we follow Abadie and Imbens (2011) who suggest to estimate ex post outcome regressions after matching. We estimate weighted linear regressions of the individual outcomes on an intercept, a treatment dummy as well as further covariates and the interactions of their demeaned values with the treatment dummy (Wooldridge, 2002, p. 612). Because of the fairly small treatment sample, we decided not to align the treated women and the women in the control group both by age and year (which would be equivalent to align age and year of birth of the women). Note that the estimated propensity score includes year dummies. Thus, the dynamic matching approach employed matches the calendar year. All estimated treatment effects reported in the following - including the baseline estimates without further controls - are based on outcome regressions controlling for year dummies to account for a time trend in female employment rates.

We adjust the approach by Abadie and Imbens to the IPW case employing a constant weight of $1 / \sum_{j=1}^{n}\left(T_{j}\right)$ for a treated woman $i$ and a weight of $\left(1-T_{j}\right) \hat{W}_{i, j} / \sum_{j=1}^{n}\left(1-T_{j}\right) \hat{W}_{i, j}$ for a nontreated woman $j$, with outcome $Y_{j, a g e(i)}$ aligned in age for $E_{i, j}=1$ to treated woman $i$.

Specifically, we run the following regression of the outcome $Y$ after the beginning of treatment

(3) $Y_{j, a g e}=\alpha+x_{j} \beta+\gamma T_{j}+T_{j}\left(x_{j}-\bar{x}\right) \delta+u_{j}$, 
where $x_{j}$ denote the observable characteristics considered, i.e. educational dummies, and $\bar{x}$ corresponds to the sample average among the treated. The outcome measurement $Y_{i, a g e}$ is recorded once for a treated woman $i$ and carries a weight of 1 . The outcome measurement $Y_{j, a g e(i)}$ for a nontreated woman $j$ is recorded as many times as she can be used as a control observation for a treated woman $i$ (each time aligned in age to $i$ ). Each single measurement carries the weight $\left(1-T_{j}\right) \hat{W}_{i, j} / \sum_{j=1}^{n}\left(1-T_{j}\right) \hat{W}_{i, j}$ and the weights of eligible control observations sum up to one for each treated woman $i$. These regression weights mimic the weights used in equation (1). Note that in a weighted regression (3) without the covariates involving $x_{j}$, the estimate for $\gamma$ would reproduce $\hat{\theta}_{B D M}$ as in equation (2).

In a weighted regression with the covariates involving $x_{j}$, the estimate for $\gamma$ corresponds to the ATT estimate, corrected for the mismatch in observable characteristics. The coefficients $\beta$ control for the impact of the characteristics on the average outcome variable. If $\delta=0$ in regression (3), then there is no linear effect heterogeneity by the level of covariates. The standard errors of the estimated regression coefficients are obtained from the bootstrap procedure for the IPW estimator by rerunning regression (3) for all resamples.

\section{Data}

The analysis is based on data from the German Socio-Economic Panel (SOEP), a yearly household survey interviewing all persons above the age of 15 . The survey collects data on employment related questions such as working hours, income and many more. It also asks for many other topics such as leisure, health, satisfaction and values. Moreover, it contains information about monthly employment status and income sources, allowing us to analyze our research question at a monthly level. The SOEP has been used in a number of studies on employment of mothers and the effects of maternity leave, see e.g. Bergemann and Riphahn (2011), Sommerfeld (2009), Vogel (2009), Wrohlich (2004), or Kreyenfeld and Hank (2000).

We use data from 1991 to 2008, because 1991 is the first year that households from East Germany were included in the panel. We drop pensioners, disabled persons, and those women just under the age of 24 years, as younger women are often still in education. In 2000, the median age at first birth was 29 years in West Germany (Pötzsch, 2005). Older women pose a problem if the selection of the control group gets too strong, as the share of women in the control group who will have a child later decreases with age. We chose age 33 as upper limit for this study, because fertility is rather stable until the age of 34 and declines strongly from age 35 onwards (Pötzsch, 2005, Stein, 1985, p. 328, Imthurna 
et al., 2008, p. 126). Importantly, women who already have a child are excluded from the data.

A childless woman can potentially give birth to her first child in any month. We therefore construct a different control group for every month, consisting of women without children. The definition of non-treatment is crucial and involves the classification window which defines treatment and control group. On the one hand, women of the control group should not have their first child in the near future to be able to sharply distinguish between treatment and control group. On the other hand, the control group should be highly comparable to the treatment group such that the probability of having a child is similar. As a compromise, we chose a window of three months during which control group individuals must not have their first child.

We also have to address attrition in the data, which has to be incorporated in the normalization of the IPW-weights. The size of the treatment and control group by age is shown in Figure 1. For the estimation of the treatment effect it is essential to match highly comparable women. This comparability is achieved by the exact alignment of age (in months) as has been described earlier, and by a reweighting procedure which is based on the propensity to have the first child at a certain age. The required pre-birth information is collected at least 12 months before the birth to avoid the anticipation of the exact timing of first birth. However, in order to use relevant information for the time of birth, the interview should not have been too far in the past; we therefore choose a maximum of 15 months before birth based on a window width of three months. Reweighting on the propensity score is required to assure that the dynamic conditional independence assumption (DCIA) holds. To capture all relevant factors which jointly influence fertility and labor supply, we include human capital variables (degree of schooling and training education), pre-birth labor market history (working hours, wage, job type, full time, part time and unemployment experience) as well as information on relationships (partnership, marriage). In addition, we include the self-reported importance of family for one's satisfaction as an attitudinal variable affecting the fertility decision.

[ Figure 1 about here. ]

Figure 2 shows the distribution of age at first birth in the age range 20 to 38 years both for all women and by education group. First childbirths for all women peak in the age range 24-33 (the age range we consider in our analysis), but a sizeable share of first childbirths occurs outside of this age range. The age distribution differs considerably by education group. The age distribution shifts to the right the higher the education level. First childbirths peak for the low-skilled mothers in their early 20 s, for the medium-skilled 
mothers in the late 20s, and for the high skilled mothers in their early 30s. Our age range 24-33 covers the vast majority of childbirths for all women and in the group of mediumskilled women. The share is lower both for low-skilled and for high-skilled women.

[ Figure 2 about here. ]

Our outcome variable of interest is employment after first birth. We provide some evidence on full time and part time employment but we focus on employment as our outcome variable of interest. Note that part time employment may be a stepping stone towards higher working hours at a later time (Vogel, 2009; Ziefle, 2004). The level of full time employment in Germany is very low after childbirth (see e.g. Geyer and Steiner, 2007; Sommerfeld, 2009). Furthermore, there is no distinction between household work (being out-of-labor) and job search (being unemployed) as the data do not allow us to distinguish between these states in a reliable way. We abstract from reductions in hours of work around the time of childbirth (Buligescu et al., 2009). Our outcome variable is employment in each month for five years following the birth of the first child. Extending the analysis to a time period beyond five years severely reduces the sample size due to sample attrition (results are available upon request).

\section{$5 \quad$ Empirical Results}

After some descriptive evidence, we discuss the estimated treatment effects and the results of a sensitivity analysis.

\subsection{Descriptive Statistics before and after IPW-matching}

Table 2 shows descriptive statistics at the time of matching before ('unweighted') and after IPW-matching ('weighted'). The probit estimates for the propensity score are displayed in Table 3. Table 2 shows that before matching, there are some sizeable differences in observables between the treatment and the control group (e.g., treated women are more often employed and live more often in a partnership). Hardly any significant differences remain after matching. Thus, IPW seems to balance the observable characteristics very well. Furthermore, Figure 3 shows that there is a very good overlap in the support of the distributions of the estimated propensity score for the treatment group and the control group.

[ Tables 2 and 3 about here. ]

[ Figure 3 about here. ] 
Figures 4 to 6 show that with respect to the employment rate, educational degrees, and partnership, some pre-birth differences between treatment and control group exist before matching (i.e. without IPW-weighting), particularly at younger ages. The highest obtained educational degrees also differ somewhat for younger women, as some of them are still in education. ${ }^{15}$ These figures also show that the weighting procedure works well to improve comparability between treatment and control group at the point in time before treatment starts. However, the employment rate of the treatment group before birth still remains slightly higher, i.e. young first-time mothers have a higher labor force attachment before birth than women of the same age, but without a child.

[ Figures 4, 5, 6 and about here. ]

Figure 7 shows employment rates before and after birth, with and without reweighting of the control group. Recall that matching takes place twelve months before treatment. The reweighting procedure works well for the alignment of the employment rate before birth, even though the treatment group still exhibits slightly higher rates. At birth, employment among the treated drops to zero due to mandatory maternity leave of at least eight weeks after the birth. Afterwards, the employment rate of first-time mothers recovers very slowly, while that of women in the control group decreases slightly. This is due to the fact that these women may also drop out of employment, e.g. due to childbirth in the future (see evidence on this below). A major concern is that the treatment group may be negatively selected with respect to unobservables, which could be reflected in the pre-birth employment dip (see Ejrnaes and Kunze (2012) for related evidence based on administrative data for a pre-birth earnings dip). However, this is unlikely to be a problem in our case because the pre-birth employment dip is restricted to about six months right before birth and because we match on the observables - including employment - twelve months before birth. Also, note that compared to the group of all nontreated women, our treatment group is a positive selection with respect to the employment rate during the time period of 24 months to six months before birth. We conclude that there is no indication that anticipation effects twelve months before birth invalidate our estimation approach.

\section{[ Figure 7 about here. ]}

Next, we consider employment rates in full time and in part time employment for the two groups. While there is a clear expectation that women in the treatment group will

\footnotetext{
${ }^{15}$ Recall that for the treatment effect at age 24 the training degree is measured at age 23 - an age where some educational programs are not yet completed (particularly university).
} 
work much less in full time than the control group, it is not that clear what to expect for part time work. As Figure 8 shows, the development of full time employment is as expected. For part time work the shares are very low before first childbirth and increase stronlgy afterwards. While the part time employment rate of the treatment group reaches more than $30 \%$ five years after first childbirth, this rate remains clearly below $20 \%$ for the control group.

[ Figure 8 about here. ]

To shed more light on the fertility behavior in the treated group and the control group, Figure 9 shows the rates at which women in the control group have their first birth and at which treated women have their second birth. It can be seen that after five years, nearly $50 \%$ of the control observations have had their first birth. Among the treated, nearly $60 \%$ have had a second birth by this time.

[ Figure 9 about here. ]

\subsection{Average Treatment Effect on the Treated (ATT)}

Recall that we estimate the ATT of the treatment of having a first child now versus waiting, where waiting entails both the possibility to have child later at a higher age and the possibility of never having a child. Figure 10 depicts the monthly ATTs on employment outcomes during the first five years after first birth. The estimates are pooled across age groups and the confidence intervals are based on 100 bootstrap replications. The estimated ATTs are negative and persistent, implying that within the observation window of five years, the first-time mothers never fully catch up to the control group. This holds even though part time employment is also covered by our outcome variable and women in the control group may also drop out of employment, e.g. because of childbirth. Over time, the ATT clearly shows a strong upward trend, however, being interrupted by short periods of decline which are due to mothers who (re)enter the labor market after childbirth, but later drop out again.

[ Figure 10 about here. ]

At time zero, which corresponds to the month of birth, the absolute values of the ATTs are highest just reflecting the employment rate in the control group, since all treated mothers are not allowed by law to work during the first two months or so. The estimated treatment effects right after birth are a kind of 'lock-in effect of childbirth', analogous to lock-in effects in the analysis of labor market programs (Fitzenberger et al., 2013). 
During the first year after childbirth, the ATT increases strongly from -81 percentage points (ppoints) to around -50 ppoints. In the second year the ATT continues to catch up, reaching -30 ppoints. Three years after birth we observe an upward jump in the ATT to -20 ppoints, which is due to the institutional changes that occur at this point in time (recall the job protection period and childcare availability). Still, this jump after three years is small. Afterwards, the negative employment effect remains fairly constant, reaching around -20 ppoints after five years. Our key finding is the large and persistent negative employment loss after first childbirth which does not level off completely within five years. Distinguishing between full time and part time employment, Figure 8 implies a positive effect of first childbirth on part time employment and a negative effect on fulltime employment. Thus, the employment loss implied by childbirth is fully explained by the loss in fulltime employment.

Figure 10 also shows employment effects before childbirth. Note that we align treated and nontreated women 12 months before birth. Consequently, there is no significant employment effect two years before birth, which shows that, after matching, treated and nontreated women are well matched with regard to their employment history. Right before birth, there is a small negative employment effect, which we denote as a lock-ineffect caused by the pregnancy - in analogy to the training literature. The future mothers start to reduce their labor supply. Note that our matching approach does not allow matched women in the control group to have their first child during the first three months after childbirth by the respective treated mother. Therefore, the control group is locked into non-treatment during this period, which is associated with a higher employment rate compared to women who have a child soon after the treated women.

Next, we discuss the employment effects by age groups to investigate whether delaying the first birth leads to distinct results. Recall that our estimation approach does not allow us to infer causal effects of delaying childbirth. Here, we simply compare the estimated ATT employment effects across age groups based on the different groups of treated women having a first child at a different age. The selection of these treated women may change over time. Because it is likely that the foregone earnings when not working are growing with age, we would expect the employment loss to fall with age. However, a changing selection of treated women by age may result in a different age pattern.

Figure 11 plots the ATT employment effects by two-year age groups, averaging treatmentcontrol differences among first-time mothers in the age group. The estimated ATTs are always negative and show similar patterns as the ones for the pooled results. Note that this similarity holds although older women show higher employment rates than younger ones in both the treatment and the control group. These differences simply cancel out 
in the estimation of the ATTs. Two years after childbirth, the employment effects for the different age groups start to diverge, with the oldest age group showing the strongest negative employment effects and the youngest age group showing ATTs approaching zero after five years. This could be due to the fact that the average age at first childbirth is about 28 years, which in turn is likely to affect the behavior of the control group of the 24-and 25-year-olds three to four years later. The differences between the groups of 26-27, 28-29, and 30-31 year-olds are negligible. At the same time, the absolute value of the ATT is very large for the oldest considered group. This group exhibits a clearly stronger effect in the second and third year after birth compared to all other age groups. One explanation for this finding could be that the utility of spending more time with the child increases with age at childbirth, thus reflecting a changing selection of mothers by age at childbirth.

[ Figure 11 about here. ]

To understand our results, it also proves important to consider how second births in the treatment group are distributed over the age groups. One would expect that older or more productive groups space their births more closely (Ejrnaes and Kunze, 2012; Troske and Voicu, 2010). The left part of Figure 12 shows that the fraction of treatment mothers who have a second child is rather stable over the age groups up until age 30-31. However, the kink in Figure 12 (left) means that the group of $32+33$ year-old first time mothers displays a lower share of second births than younger mothers. The right part of Figure 12 shows that the fraction of control women who have a first child within two years after the treatment women is constant over age. However, what declines with age is the fraction of control observations who have a first child three to five years after the matched treatment observations.

[ Figure 12 about here. ]

Among the results obtained so far, the most striking part is the large negative employment effects for the group of 32-33 year-olds although this group displays a very high labor force attachment before birth. This contradicts predictions derived from human capital theory saying that the ATT should be lower for older first-time mothers as they have already acquired a high level of human capital through work experience. Additionally, this is against the findings of Miller (2011) and Troske and Voicu (2010) who both find higher labour force attachments of mothers who delay the first birth.

Education may also affect the timing of labor market entry, career progression, and the timing of birth. In Germany, young employees with a vocational training degree generally 
enter the labor market in their early twenties at the latest. University students typically complete their university degree in their mid/late twenties. When highly educated women anticipate large wage losses (as found by Wilde et al., 2010; Ejrnaes and Kunze, 2012), it is rational for them to return to the labor market more quickly than others. For these reasons, we expect a smaller reduction and a stronger recovery in employment rates after birth for university graduates compared to other education groups, a prediction which is confirmed by Figure 13. We find that the estimated loss decreases with education. However, these results may be affected by selection since highly educated women give birth at higher age compared to the other two education groups (see figure 2) and their unobserved characteristics might be different.

[ Figure 13 about here. ]

[ Figure 14 about here. ]

As mentioned before, career progression of young women in Germany differs largely by education group since university graduates enter the labor market much later than the two other education groups. Thus, for university graduates, the time span to space births may be shorter. This raises the question whether ATTs in the oldest age groups differ by education. Figure 15 depicts the ATTs for the three highest age groups and for women with university degree versus women with training or apprenticeship degree (further results are available upon request). We find huge differences both between and within education groups. Women with training or apprenticeship degree exhibit the largest negative ATTs in the oldest age group. In contrast, women with a university degree already catch up with the control group after 15 months, when they are at least 30 years old. These results show a notable difference in the behavior of medium-skilled and high-skilled women in Germany. Only for the latter group, the findings are in line with theoretical predictions and with U.S. findings.

[ Figure 15 about here. ]

To summarize the magnitude of employment losses due to birth of the first child, table 4 reports cumulative employment losses in person-months. During the first five years after birth, an average of about two years (23 months or 38.5\%) in employment are 'lost' due to having a child now instead of waiting.

[ Table 4 about here. ] 
Overall, in contrast to the literature (Troske and Voicu, 2011; Miller, 2011), our results do not provide support for the hypothesis that delayed childbirth leads to higher employment. However, one has to recall at this point that we estimate a different parameter. Troske and Voicu (2011) estimate the effect of having a child versus not having a child, where not having a child does not entail the possibility of having a child in the future. Given that a larger share of women in the control group have a child in the near future and given that this share is falling with age (Figure 12), we would expect a disproportionately higher employment rate in our control group at higher age compared to Troske and Voicu (2011), according to our case of stronger negative employment effects at an older age. The argument is supported because the negative effect is mainly driven by the medium skilled and, in fact, for older first-time mothers employment rates are larger in the control group of medium skilled women compared to the control group of high skilled women. To put this into perspective, one should note the fairly late labor market entry of high skilled women in Germany (Hochschulrektorenkonferenz (HRK), 2010).

In contrast to Troske and Voicu (2011), Miller (2011) provides IV-estimates which only contrast mothers at different age at the point of childbirth, i.e. in her approach, the control group used does not include women who do not have a child. Based on the same argument as above, one would also expect that our results show a stronger negative employment effect at higher age of birth compared to Miller (2011).

In addition, the characteristics of the treated individuals change with age at birth. Strictly speaking, when employment effects vary with observable and unobservable characteristics, it is not possible to compare the ATT estimates obtained for different age groups because the two treatment groups are not balanced in their characteristics. It would be possible to reweight the two groups in order to make them comparable regarding observables. However, it is likely that they also differ in unobservables which would require further assumptions and a different estimation approach to balance. Thus, the difference between our results and the literature may also be caused by differences in the composition of mothers by age at childbirth.

Finally, the institutional differences between Germany and the U.S. are likely reasons for the differences in results. A large share of medium-skilled women in Germany take up the three-year period of job protection implied by maternity leave coverage in Germany and medium-skilled women tend to have their first child at a fairly high age. These women generally have acquired a sizeable period of job experience and the career costs associated with first childbirth are presumably quite high. Nevertheless, it is likely that this group of women live in male-breadwinners partnerships for which the perceived utility of fulltime childcare during the first years of the child's life exceeds the utility of a return to job. 
The German tax system and maternity leave institutions strongly support this behavior. In comparison, high-skilled women seem to be less affected by the institutional incentives for taking long breaks from employment.

\subsection{Time Trend and 2001 Reform}

Now, we investigate whether the employment implied by first childbirth falls over the course of our observation period. Specifically, we allow our ATT estimates to depend upon a linear trend. ${ }^{16}$ Figure 16 shows that the time trend is significantly positive (see year specific coefficients depicted in the figure to the left). The employment loss falls by about 0.5 percentage points per calendar year during the first year after childbirth and by around 1.5 percentage points per calendar year afterwards. The figure to the right shows the estimated implied ATT (based on observable characteristics of all treated) for a childbirth in the year 1993 and a childbirth in the year 2003. Over the course of ten years the employment loss during the fifth year after childbirth falls from about 40 percent to about 20 percent. There is an apparent trend towards a reduction of the employment loss implied by the birth of a first child reflecting a continuous change in the behavior of first-time mothers during the 1990s and 2000s. This may reflect changing social norms towards employment of mothers of young children.

[ Figure 16 about here. ]

We also investigate whether we can find a significant effect of the policy reform in 2001, whose intention was to increase the employment of mothers after birth. As described in section 2, parents were now allowed to work up to 30 instead of 19 hours per week while being in parental leave. They were additionally given the choice to either claim higher parental leave benefits over the period of 12 months, or to claim a lower benefit paid over a longer period of 24 months. Furthermore, full time workers were entitled to switch to part time work within their jobs, a change which was however not limited to parents only (the title of the new law was "Teilzeit- und Befristungsgesetz"). These legal changes were introduced at the same time and we will therefore estimate their joint effect on the ATT of first birth on employment from 2001 onwards after having accounted for a linear time trend in the treatment effect. Due to a small sample size, we cannot evaluate the policy reform by using a regression discontinuity design.

\footnotetext{
${ }^{16}$ The time trend is measured by interactions of dummy variables for years since birth with calendar year of observation. The sample size is insufficient to use interactions at the monthly frequency.
} 
The reform effect is estimated by means of regression (3) interacting dummy variables for years since birth with a dummy variable for the time period starting in $2001 .{ }^{17}$ We find that the reform effect is insignificant (detailed results are not reported here, but they are available upon request). Thus, we do not find a significant effect of the reform itself. Rather, it seems that the reform accommodates a general trend towards higher employment after first birth.

\subsection{Sensitivity Analysis}

In order to check the sensitivity and robustness of our results and to analyze the main determinants of our results, we now discuss some alternative estimates for comparison.

First, we implement the dynamic approach outlined in section 3.1, but without inverse probability weighting (section 3.2), i.e. we only align mothers and not-yet-mothers by age at childbirth and then contrast mean employment rates by age of the child, see Figure 17. Despite small changes, the qualitative results remain unchanged. Thus, selection on observables (as observed twelve months before birth), apart from age and not having had a child until the date of birth, apparently is not important for the estimation of the treatment effect. This surprising result deserves some further discussion. Our data include detailed information on the partner of the women and on subjective attitudes towards family. It is because of the availability of such variables that we use the GSOEP, which is a household survey, in the first place as opposed to administrative data (as used e.g. by Simonsen and Skipper (2006); Ejrnaes and Kunze (2012)). Our results suggest that age at birth is the key selection variable to control for. Ex post, our results can be in fact be interpreted as justification for using administrative data with much larger sample sizes but with little or no information about the household context and no information about attitudes.

[ Figure 17 about here. ]

Second, we drop the condition that women in the control group may not have a child within three months after the treatment group. Instead, they may now have their first child at any time after the treatment group. There is no discernible difference in the result, see Figure 18.

[ Figure 18 about here. ]

\footnotetext{
${ }^{17}$ The time trend is measured by interactions of dummy variables for years since birth with year of observation minus mean year of all observed first births (i.e. 2000).
} 
The third sensitivty check relates to the previous one: we vary the control group by using only soon-to-be-mothers (conceptually similar to Miller, 2011; Wilde et al., 2010) and by using only childless women (conceptually similar to Troske and Voicu 2010, 2011). Note that this means conditioning on future outcomes (Fredriksson and Johansson, 2008). Specifically, we first use as control group only women who give first birth between 3 and 24 months after the respective treated woman has had her first child. The second alternative control group only consists of women who do not give birth to a child within 5 years after the childbirth of the respective treated woman. The results are presented in Figure 19. For the first case, a lock-in effect of 12 months shortly after birth is observed. During the second year there is a slightly positive effect of up to 11 ppoints. Afterwards, no significant effect can be observed. This means that the treatment and the control group exhibit similar employment rates in the long-run. For the second case, the pattern looks similar to the overall ATT, but the negative effect stays above 40 ppoints until the end of the observation period. Here, women who never have children probably drive the result.

[ Figure 19 about here. ]

Fourth, we use a different selection of the treatment group to check the sensitivity of results. Figure 20 excludes all women from the treatment group who have a second child during the observation period of five years. We find that the employment loss gradually declines and becomes zero after five years. Although this definition of the treatment group conditions on future outcomes, the results suggest that the remaining significant employment loss after five years reported in section 5.2 is driven by the fact that many mothers have a second child during the first five years after first childbirth.

[ Figure 20 about here. ]

Last but not least, we investigate as to whether the results are sensitive to panel attrition. Figure 21 limits the sample to those women who are still observed in the data 5 years after first childbirth by the respective treated woman. Constrasting Figures 10 and 21 , it is quite reassuring that the results do not change in a substantive way.

[ Figure 21 about here. ] 


\section{Conclusions}

Between age 20 and age 40, women have to jointly take crucial career and fertility decisions. The impact of childbirth on career outcomes varies greatly with human capital and, thus, with age. The literature suggests that delaying the first childbirth pays off by faster career progression. This paper studies the effect of having a first child at a certain age against the alternative of delaying first childbirth at that age on subsequent employment. To address this question, we start from the individual decision whether to have the first child now or wait. This is modeled in a dynamic treatment effects framework in analogy to Sianesi $(2004,2008)$ and Fitzenberger et al. (2013). We match treated and controls using inverse probability weighting (IPW) with weights normalized to sum up to one (Busso et al., 2009). Finally, using ex-post outcome regressions as discussed in Abadie and Imbens (2011) we analyze effect heterogeneity by education group, age, and time.

Our results involve large and persistent negative causal effects of first childbirth on subsequent employment. Although the employment loss is reduced over the course of the first five years following childbirth, the overall treatment effects do not level off to zero at the end of that period, i.e. the employment rates of the treatment group do not catch up completely to the control group. In other words, and in accordance with the bulk of the literature, having a child causes a sizeable employment loss. Furthermore, our findings indicate that university graduates face significantly smaller employment losses after childbirth compared to other education groups, a finding which is in line with human capital theory. The strong negative effects for the oldest considered age group of 32-33 year-olds is mainly driven by an even stronger negative effect of medium educated women. It contradicts expectations from human capital theory according to which these women face high opportunity costs of leaving the labor market. Medium-skilled women seem to take long leaves from employment - a point which has become a policy concern in times of labor shortages as a result of demographic change. Additional results show that there is an apparent trend towards a reduction of the employment loss implied by the birth of a first child reflecting a continuous change in the behavior of first-time mothers during the 1990s and 2000s. Contrasting births in 1993 and 2003, the employment loss during the fifth year after childbirth falls from about 40 percent to about 20 percent.

Our analysis conducts a number of sensitivity checks. We find that selection on observables, apart from age and not having had a child until the date of birth, apparently is not important for the estimation of the treatment effect. Rather, age at first childbirth is the key selection variable to control for. Furthermore, the qualitative pattern of our results are driven by the employment pattern of those women in the control group who 
do not have a child within the first five years after first childbirth of the treated women, and the persistent negative employment effect after five years is driven by those treated women who have a second child during the first five years after first childbirth. Our results are unaffected by excluding as controls mothers who give birth within three months after the birth considered as treatment. We conclude that anticipation effects do not invalidate our results.

By and large, our results do not provide support for the hypothesis that delayed childbirth leads to higher employment, which some of the literature finds evidence for (Troske and Voicu, 2011; Miller, 2011). However, one has to emphasize that we estimate a different parameter than these studies. Specifically, we contrast the age specific employment effects of first child birth now versus waiting, while (Troske and Voicu, 2011) and Miller (2011) estimate the causal effect of delaying child birth. Finally, we note that in a time period of increasing female labor market participation, huge investments in formal childcare for young children, various policy reforms, and increasing employer efforts supporting work life balance, employment losses of women associated with first childbirth are still huge in Germany, especially for the medium-skilled. Therefore, policy should pay particular attention to this group, which involves the majority of women. More research is necessary to scrutinize the mechanisms behind our findings. 


\section{References}

Abadie, A. and Imbens, G. W. (2011). Bias Corrected Matching Estimators for Average Treatment Effects. Journal of Business 83 Economic Statistics, 29(1):1-11.

Abbring, J. and van den Berg, G. (2003). The Nonparametric Identification of Treatment Effects in Duration Models. Econometrica, 71:1491-1517.

Angrist, J. D. and Evans, W. N. (1998). Children and Their Parents' Labor Supply: Evidence from Exogenous Variation in Family Size. American Economic Review, 88(3):450-477.

Baker, M. and Milligan, K. (2008). How Does Job-Protected Maternity Leave Affect Mothers' Employment? Journal of Labor Economics, 26:655-691.

Beblo, M. and Wolf, E. (2002). How Much Does a Year Off Cost? Estimating the Wage Effects of Employment Breaks and Part-Time Periods. Brussels Economic Review - Cahiers Econonomiques de Bruxelles, 45:191-217.

Bergemann, A. and Riphahn, R. T. (2011). Female Labor Supply and Parental Leave Benefits - The Causal Effect of Paying Higher Transfers for a Shorter Period of Time. Applied Economics Letters, $18: 17-20$.

Boll, C. (2009). Lohneinbußen durch Erwerbsunterbrechungen - fertilitätstheoretische Fundierung, Quantifizierung auf Basis von SOEP-Daten und familienpolitische Implikationen. SOEPpapers on Multidisciplinary Panel Data Research, 160.

Bronars, S. J. and Grogger, J. (1994). The economic consequences of unwed motherhood: Using twin births as a natural experiment. American Economic Review, 84(5):1141-1156.

Buligescu, B., de Crombrugghe, D., Menteşoğlu, G., and Montizaan, R. (2009). Panel Estimates of the Wage Penalty for Maternal Leave. Oxford Economic Papers, 61:i35-i55.

Busso, M., DiNardo, J., and McCrary, J. (2009). New Evidence on the Finite Sample Properties of Propensity Score Matching and Reweighting Estimators. IZA Discussion Paper, 3998.

Ciliberto, F., Miller, A. R., Nielsen, H. S., and Simonsen, M. (2012). Playing the Fertility Game at Work: An Equilibrium Model of Peer Effects. Mimeograph.

Cristia, J. P. (2008). The Effect of a First Child on Female Labor Supply - Evidence from Women Seeking Fertility Services. The Journal of Human Resources, 43(3):487-510.

Dustmann, C. and Schönberg, U. (2012). The Effect of Expansions in Maternity Leave Coverage on Children's Long-Term Outcomes. American Economic Journal: Applied Economics, 4(3):190-224.

Ejrnaes, M. and Kunze, A. (2012). Work and Wage Dynamics around Childbirth. Forthcoming in Scandinavian Journal of Economics.

Fernandez-Kranz, D., Lacuesta, A., and Rodriguez-Planas, N. (2013). The Motherhood Earnings Dip Evidence from Administrative Records. The Journal of Human Resources, 48:169-197. 
Fitzenberger, B., Orlanski, O., Osikominu, A., and Paul, M. (2013). Déjà Vu? Short-term Training in Germany 1980-1992 and 2000-2003. Empirical Economics, 44(1):289-328.

Fortin, N. (2009). Gender Role Attitudes and Women's Labor Market Participation: Opting-Out, AIDS, and the Persistent Appeal of Housewifery. Unpublished Manuscript, University of British Columbia, Vancouver.

Fredriksson, P. and Johansson, P. (2008). Dynamic Treatment Assignment: The Consequences for Evaluations Using Observational Data. Journal of Business and Economic Statistics, 26:435-445.

Frölich, M. (2004). Finite-Sample Properties of Propensity-Score Matching and Weighting Estimators. The Review of Economics and Statistics, 86(1):77-90.

Geyer, J. and Steiner, V. (2007). Short-Run and Long-Term Effects of Childbirth on Mother's Employment and Working Hours Across Institutional Regimes: An Empirical Analysis Based on the European Community Household Panel. IZA Discussion Paper, 2693.

Goldin, C. (2006). The Quiet Revolution That Transformed Women's Employment, Education, and Family. American Economic Review, Papers and Proceedings, 96:1-21.

Gustafsson, S. S., Wetzels, C. M., Vlasblom, J. D., and Dex, S. (1996). Women's Labor Force Transitions in Connection with Childbirth: A Panel Data Comparison Between Germany, Sweden and Great Britain. Journal of Population Economics, 9:223-246.

Herr, J. L. (2009). Decomposing the Effect of First Birth Timing on Women's Wage Growth. Paper presented at the APPAM Fall Conference.

Herr, J. L. (2011). Measuring the Effect of the Timing of First Birth. Unpublished Discussion Paper, The Harris School of Public Policy Studies, University of Chicago.

Hirano, K., Imbens, G. W., and Ridder, G. (2003). Efficient Estimation of Average Treatment Effects Using the Estimated Propensity Score. Econometrica, 71(4):1161-1189.

Hochschulrektorenkonferenz (HRK) (2010). Statistiken zur Hochschulpolitik 2/2010.

Hotz, J. V. and Miller, R. A. (1988). An Empirical Analysis of Life Cycle Fertility and Female Labor Supply. Econometrica, 56(1):91-118.

Imthurna, B., Maurer-Majorb, E., and Stillera, R. (2008). Sterilität/ Infertilität - Ursachen und Abklärung. Swiss Medical Forum, 8(7):124-130.

Kluve, J. and Tamm, M. (2012). Parental Leave Regulations, Mothers' Labor Force Attachment and Fathers' Childcare Involvement: Evidence from a Natural Experiment. Forthcoming in Journal of Population Economics.

Kreyenfeld, M. (2001). Employment and Fertility - East Germany in the 1990s. PhD thesis, Max-Planck Institute for Demographic Research, Rostock.

Kreyenfeld, M. and Hank, K. (2000). Does the Availability of Child Care Influence the Employment of Mothers? Findings from Western Germany. Population Research and Policy Review, 19:317-337. 
Lalive, R. and Zweimüller, J. (2009). How Does Parental Leave Affect Fertility and Return-to-Work? Evidence from Two Natural Experiments. Quarterly Journal of Economics, 124(3):1363-1402.

Lechner, M. (2009). Sequential Causal Models for the Evaluation of Labor Market Programs. Journal of Business 83 Economic Statistics, 27(1):71-83.

Lefebvre, P., Merrigan, P., and Verstraete, M. (2009). Dynamic Labour Supply Effects of Childcare Subsidies: Evidence from a Canadian Natural Experiment on Low-Ffee Universal Child Care. Labour Economics, 16:490-502.

Mühler, G. (2010). Consequences of Mixed Provision of Child Care - An Overview on the German Market. ZEW Discussion Paper, 08-077 (2nd version).

Miller, A. R. (2011). The Effects of Motherhood Timing on Career Path. Journal of Population Economics, 24(3):1071-1100.

Millimet, D. L. (2000). The impact of children on wages, job tenure, and the division of household labour. The Economic Journal, 110:C139-C157.

OECD, editor (2002). OECD Employment Outlook, Chapter 2, Women At Work: Who are They and How are They Faring? Organisation for Economic Co-operation and Development, Paris.

OECD, editor (2007). Babies and Bosses. Reconciling Work and Family Life. A Synthesis of Findings for OECD Countries. Organisation for Economic Co-operation and Development, Paris.

Ondrich, J., Spieß, C. K., and Yang, Q. (1996). Barefoot and in a German Kitchen: Federal Parental Leave and Benefit Policy and the Return to Work After Childbirth in Germany. Journal of Population Economics, 9:247-266.

Ondrich, J., Spieß, C. K., Yang, Q., and Wagner, G. G. (1999). Full Time or Part Time? German Parental Leave Policy and the Return to Work After Childbirth in Germany. Research in Labor Economics, 18:41-74.

Ondrich, J., Spieß, C. K., Yang, Q., and Wagner, G. G. (2003). The Liberalization of Maternity Leave Policy and the Return to Work After Childbirth in Germany. Review of Economics of the Household, 1(1-2):77-110.

Pötzsch, O. (2005). Unterschiedliche Facetten der Geburtenentwicklung in Deutschland. Wirtschaft und Statistik, 6:569-581.

Schönberg, U. and Ludsteck, J. (2012). Expansions in Maternity Leave Coverage and Mothers' Labor Market Outcomes after Childbirth. Journal of Labor Economics, conditionally accepted.

Sianesi, B. (2004). An Evaluation of the Swedish System of Active Labor Market Programs in the 1990s. The Review of Economics and Statistics, 86(1):133-155.

Sianesi, B. (2008). Differential Effects of Swedish Active Labor Market Programs for the Unemployed. Labour Economics, 15(3):370-399. 
Simonsen, M. and Skipper, L. (2006). The Costs of Motherhood: An Analysis Using Matching Estimators. Journal of Applied Econometrics, 21:919-934.

Sommerfeld, K. (2009). Older Babies - More Active Mothers? How Maternal Labor Supply Changes as the Child Grows. Schmollers Jahrbuch: Journal of Applied Social Science Studies, 129(2):227-240.

Stein, Z. A. (1985). A Woman's Age: Childbearing and Child Rearing. American Journal of Epidemiology, 121(3):327-342.

Troske, K. R. and Voicu, A. (2009). The Effect of Children on the Level of Labor Market Involvement of Married Women: What is the Role of Education? IZA Discussion Paper, 4074.

Troske, K. R. and Voicu, A. (2010). Joint Estimation of Sequential Labor Force Participation and Fertility Decisions Using Markov Chain Monte Carlo Techniques. Labour Economics, 17(1):150 - 169.

Troske, K. R. and Voicu, A. (2011). A Panel Data Analysis of Racial/Ethnic Differences in Married Women's Labor Supply. IZA Discussion Paper, 5729.

Troske, K. R. and Voicu, A. (2012). The Effect of the Timing and Spacing of Births on the Level of Labor Market Involvement of Married Women. Empirical Economics, Online.

van Ham, M. and Büchel, F. (2004). Females' Willingness to Work and the Discouragement Effect of a Poor Local Childcare Provision. Applied Economics Quarterly, 4:363-377.

Vogel, C. (2009). Teilzeitbeschäftigung - Ausmaß und Bestimmungsgründe der Erwerbsübergänge von Frauen. Zeitschrift für ArbeitsmarktForschung - Journal for Labor Market Research (ZAF), 42(2):170181.

Waldfogel, J. (1998). Understanding the "family gap" in pay for women with children. The Journal of Economic Perspectives, 12:137-156.

Waldfogel, J. (1998b). The family gap for young women in the united states and britain: can maternity leave make a difference? Journal of Labor Economics, 16:505-545.

Wilde, E. T., Batchelder, L., and Ellwood, D. T. (2010). The Mommy Track Divides: The Impact of Childbearing on Wages of Women of Differing Skill Levels. NBER Working Paper, 16582.

Wooldridge, J. M. (2002). Econometric Analysis of Cross Section and Panel Data. The MIT Press.

Wrohlich, K. (2004). Child Care Costs and Mother's Labor Supply: An Empirical Analysis for Germany. DIW Discussion Paper, 412.

Ziefle, A. (2004). Die individuellen Kosten des Erziehungsurlaubs: Eine empirische Analyse der kurzund längerfristigen Folgen für den Karriereverlauf von Frauen. Wissenschaftszentrum Berlin für Sozialforschung (WZB). 


\section{Appendix}

Table 1: Child allowance by birth order in Euro

\begin{tabular}{|l|cccc|}
\hline \hline Year & 1st child & 2nd child & 3rd child & Higher parity \\
\hline $1992-1995$ & 35.79 & 66.47 & 112.48 & 122.71 \\
1996 & 102.26 & 102.26 & 153.39 & 178.95 \\
$1997-1998$ & 112.48 & 112.48 & 153.39 & 178.95 \\
1999 & 127.82 & 127.82 & 153.39 & 178.95 \\
$2000-2001$ & 138.05 & 138.05 & 153.39 & 178.95 \\
$2002-2008$ & 154.00 & 154.00 & 154.00 & 179.00 \\
\hline \hline
\end{tabular}


Table 2: Characteristics at time of matching, i.e. 1 year before birth

Treatment group

Control group

Unweighted

IPW-weighted

\begin{tabular}{lrrrrrr} 
& Value & \multicolumn{1}{c}{$[\mathrm{CI}]$} & Value & {$[\mathrm{CI}]$} & Value & {$[\mathrm{CI}]$} \\
\hline & & & & & & \\
Outcome-variable: Employed & $82.4 \%$ & {$[79.0 ; 85.8]$} & $73.2 \%$ & {$[72.0 ; 74.4]$} & $80.7 \%$ & {$[78.8 ; 82.6]$} \\
& & & & & & \\
Wage & 9.98 & {$[9.59 ; 10.38]$} & 9.32 & {$[9.06 ; 9.57]$} & 9.51 & {$[9.14 ; 9.85]$} \\
Working hours & 35.3 & {$[34.0 ; 36.6]$} & 31.7 & {$[31.2 ; 32.2]$} & 34.8 & {$[33.8 ; 35.9]$} \\
Part time & $7.8 \%$ & {$[5.2 ; 10.5]$} & $9.9 \%$ & {$[9.1 ; 10.6]$} & $7.0 \%$ & {$[5.2 ; 8.8]$} \\
& & & & & & \\
Job status: & & & & & & \\
Not employed & $7.2 \%$ & {$[5.4 ; 9.1]$} & $6.3 \%$ & {$[5.6 ; 7.0]$} & $6.7 \%$ & {$[5.4 ; 8.1]$} \\
In Training & $5.9 \%$ & {$[3.7 ; 8.0]$} & $15.6 \%$ & {$[14.5 ; 16.6]$} & $8.5 \%$ & {$[7.0 ; 9.4]$} \\
Blue collar & $11.9 \%$ & {$[9.0 ; 14.7]$} & $9.7 \%$ & {$[8.8 ; 10.6]$} & $12.5 \%$ & {$[10.0 ; 15.0]$} \\
Self-employed & $2.6 \%$ & {$[1.2 ; 3.9]$} & $2.8 \%$ & {$[2.1 ; 3.4]$} & $2.4 \%$ & {$[1.3 ; 3.5]$} \\
White collar & $64.9 \%$ & {$[60.4 ; 69.4]$} & $60.2 \%$ & {$[58.5 ; 61.8]$} & $63.1 \%$ & {$[60.4 ; 66.3]$} \\
Civil servant & $7.6 \%$ & {$[5.1 ; 10.1]$} & $5.5 \%$ & {$[4.7 ; 6.2]$} & $6.8 \%$ & {$[5.2 ; 8.5]$} \\
& & & & & & \\
Work experience (in years) in... & & & & & & \\
... Full time & 5.16 & {$[4.87 ; 5.45]$} & 4.18 & {$[4.05 ; 4.32]$} & 4.92 & {$[4.71 ; 5.13]$} \\
... Part time & 0.68 & {$[0.54 ; 0.83]$} & 0.83 & {$[0.76 ; 0.90]$} & 0.64 & {$[0.56 ; 0.72]$} \\
... Unemployment & 0.29 & {$[0.23 ; 0.35]$} & 0.33 & {$[0.29 ; 0.37]$} & 0.28 & {$[0.24 ; 0.33]$}
\end{tabular}

Education:

University degree

$16.4 \% \quad[13.2 ; 19.6]$

$15.8 \%$

$[14.5 ; 17.1]$

$14.5 \%$

$[12.2 ; 16.9]$

Training degree

$66.1 \% \quad[62.4 ; 69.9]$

$58.5 \%$

$[56.6 ; 60.4]$

$65.3 \%$

$[61.9 ; 68.6]$

No degree

Currently in education

$10.6 \% \quad[7.9 ; 13.4]$

$9.0 \%$

$[7.8 ; 10.2]$

$12.2 \%$

$[10.0 ; 14.5]$

$6.8 \% \quad[4.6 ; 9.1]$

$16.7 \%$

$[15.6 ; 17.9]$

$7.9 \%$

$[6.5 ; 9.4]$

Currently in partnership

$85.6 \%$

$[82.3 ; 88.8]$

$73.7 \%$

$[72.5 ; 75.0]$

$85.9 \%$

$[83.8 ; 87.9]$

Partner info missing (no partner)

$25.9 \%$

$[21.9 ; 29.9] \quad 57.8 \%$

$[56.0 ; 59.7]$

$25.2 \%$

$[22.7 ; 27.9]$

Partner's earnings in Euro

$1749 \quad[1600 ; 1898]$

$954 \quad[903 ; 1005]$

$1734 \quad[1616 ; 1844]$

Importance of family...

... very high

$\begin{aligned} 48.2 \% & {[44.1 ; 52.2] } & 42.5 \% & {[40.5 ; 44.5] } & 47.9 \% & {[44.6 ; 51.2] } \\ 8.7 \% & {[6.2 ; 11.2] } & 13.5 \% & {[12.1 ; 14.8] } & 9.0 \% & {[7.1 ; 10.8] } \\ 0.4 \% & {[-0.2 ; 0.9] } & 1.7 \% & {[0.6 ; 2.8] } & 0.3 \% & {[-0.1 ; 0.7] } \\ 42.8 \% & {[38.5 ; 47.1] } & 42.3 \% & {[40.5 ; 44.1] } & 42.8 \% & {[39.4 ; 46.2] }\end{aligned}$

... high

... low or very low

... missing

818

$106,057^{*}$

$106,057^{*}$

Note: Percentage values refer to Dummy variables.

Note: CI denotes the confidence interval which is based on 100 bootstrap replications.

* Note that control observations have been replicated for technical reasons. 
Table 3: Probit regression results for having first child next year

\begin{tabular}{|c|c|c|c|}
\hline Variable & Coefficient & (Std. Err.) & Significance \\
\hline Wage & -0.001 & $(0.003)$ & \\
\hline Actual working hours & 0.002 & $(0.002)$ & \\
\hline Part time & -0.048 & $(0.070)$ & \\
\hline Blue collar & 0.038 & $(0.049)$ & \\
\hline Self-employed & 0.118 & $(0.110)$ & \\
\hline Civil servant & 0.102 & $(0.066)$ & \\
\hline Employer mainly publicly owned & 0.011 & $(0.046)$ & \\
\hline Experience full time & 0.007 & $(0.073)$ & \\
\hline Experience part time & -0.067 & $(0.116)$ & \\
\hline Experience unemployment & 0.213 & $(0.199)$ & \\
\hline Experience full time squared & 0.000 & $(0.002)$ & \\
\hline Experience part time squared & -0.002 & $(0.003)$ & \\
\hline Experience unemployment squared & 0.002 & $(0.008)$ & \\
\hline No training degree & 0.159 & $(0.435)$ & \\
\hline University degree & -0.652 & $(0.514)$ & \\
\hline In education (or educational info missing) & -0.108 & $(0.062)$ & * \\
\hline Living in East & -0.063 & $(0.178)$ & \\
\hline Partnership & -0.197 & $(0.051)$ & $* * *$ \\
\hline Partner's age & -0.039 & $(0.027)$ & $* * *$ \\
\hline Partner's age squared & 0.000 & $(0.000)$ & \\
\hline Age difference & 0.059 & $(0.012)$ & $* * *$ \\
\hline Partner high education & 0.396 & $(0.289)$ & \\
\hline Partner medium education & 0.407 & $(0.288)$ & \\
\hline Partner low education & 0.395 & $(0.289)$ & \\
\hline Partner's gross earnings & 0.000 & $(0.000)$ & \\
\hline Partner's earnings missing & -0.028 & $(0.069)$ & \\
\hline No partner info & -1.398 & $(0.560)$ & $* *$ \\
\hline Age*Importance of family very high & -0.003 & $(0.003)$ & \\
\hline Age*Importance of family high & -0.005 & $(0.003)$ & \\
\hline Age*Importance of family low or very low & -0.014 & $(0.011)$ & \\
\hline \multicolumn{4}{|c|}{ No. of years since when importance of family was last asked $* \ldots$} \\
\hline ...Importance of family very high & -0.081 & $(0.080)$ & \\
\hline ...Importance of family high & -0.047 & $(0.137)$ & \\
\hline ...Importance of family low or very low & 0.146 & $(0.754)$ & \\
\hline ...Age*Importance of family very high & 0.003 & $(0.003)$ & \\
\hline ...Age*Importance of family high & 0.003 & $(0.005)$ & \\
\hline ...Age*Importance of family low or very low & -0.005 & $(0.028)$ & \\
\hline
\end{tabular}

$<$ Table continued on next page. $>$ 
Table 3: Probit regression results for having first child next year $<$ continued $>$

\begin{tabular}{lrcc}
\hline Variable & Coefficient & (Std. Err.) & Significance \\
\hline Age 23 & 0.039 & $(0.068)$ & \\
Age 24 & 0.102 & $(0.067)$ & \\
Age 25 & 0.047 & $(0.073)$ & \\
Age 26 & 0.202 & $(0.076)$ & $* * *$ \\
Age 27 & 0.223 & $(0.086)$ & $* * *$ \\
Age 28 & 0.266 & $(0.098)$ & $* * *$ \\
Age 29 & 0.208 & $(0.117)$ & $*$ \\
Age 30 & 0.320 & $(0.137)$ & $* *$ \\
Age 31 & 0.130 & $(0.168)$ & \\
Age 32 & 0.200 & $(0.198)$ & \\
Age*Married & 0.016 & $(0.001)$ & $* * *$ \\
Age*Experience full time & 0.000 & $(0.003)$ & \\
Age*Experience part time & 0.003 & $(0.004)$ & \\
Age*Experience unemployment & -0.008 & $(0.008)$ & \\
Age*No training degree & -0.004 & $(0.017)$ & \\
Age*University degree & 0.024 & $(0.018)$ & \\
Age*In education & -0.005 & $(0.018)$ & \\
After law change & -0.318 & $(0.097)$ & $* * *$ \\
Unemployment rate & 0.034 & $(0.016)$ & $* *$ \\
Intercept & -1.314 & $(0.571)$ & $* *$ \\
Number of observations & & & \\
\hline \hline
\end{tabular}

Note: Year dummies, federal states, and firm size have been controlled for.

Note: ${ }^{*} /{ }^{* *} /{ }^{* * *}$ means significance on the $10 \% / 5 \% / 1 \%$-level, respectively.

Note: The Pseudo- $\mathrm{R}^{2}$ is 0.0878 . 
Table 4: Cumulative employment losses (in person-months)

\begin{tabular}{lrr|rrr}
\hline \hline & & \multicolumn{3}{c}{ By Training Degree } \\
& Absolute & In Percent & No training & Training University \\
\hline & & & & & \\
After 1 year & -8.71 & $-72.5 \%$ & -8.64 & -9.20 & -8.61 \\
After 2 years & -13.77 & $-57.4 \%$ & -14.40 & -14.73 & -12.76 \\
After 3 years & -17.57 & $-48.8 \%$ & -18.88 & -18.78 & -15.69 \\
After 4 years & -20.60 & $-42.9 \%$ & -22.14 & -22.25 & -16.91 \\
After 5 years & -23.10 & $-38.5 \%$ & -25.10 & -24.98 & -17.87 \\
\hline \hline
\end{tabular}


Figure 1: Size of treatment (left) and control group (right), by age
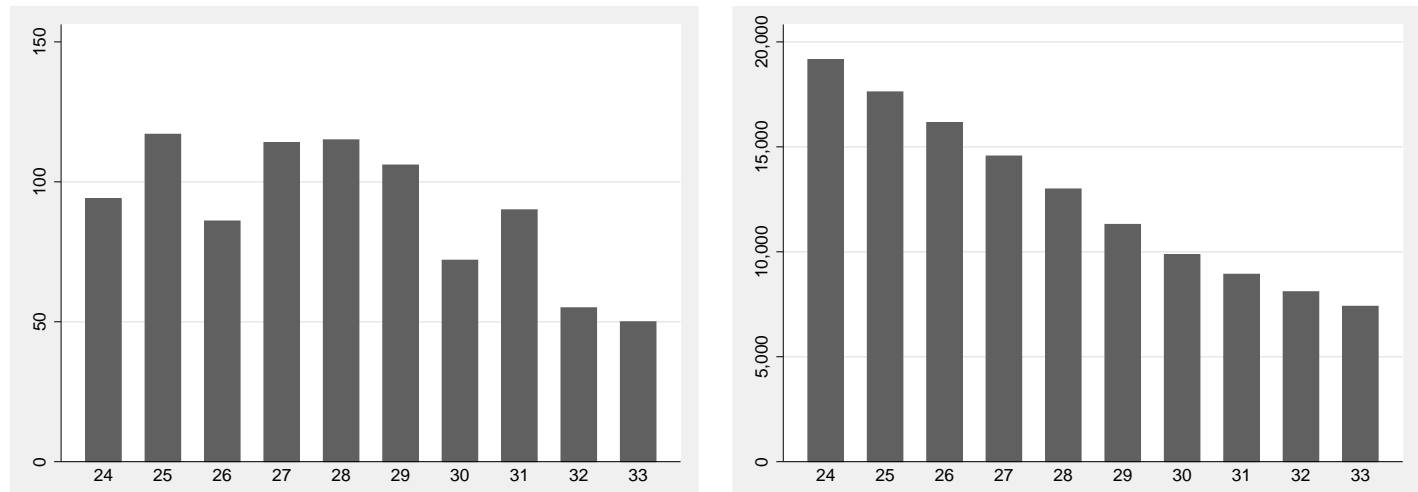

Figure 2: Age distribution at first birth in the age range 20 to 38 years All observations

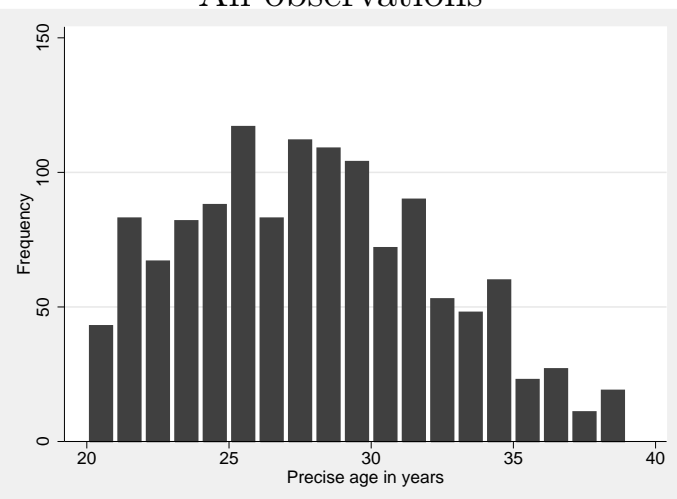

No training degree

Training/ Apprenticeship
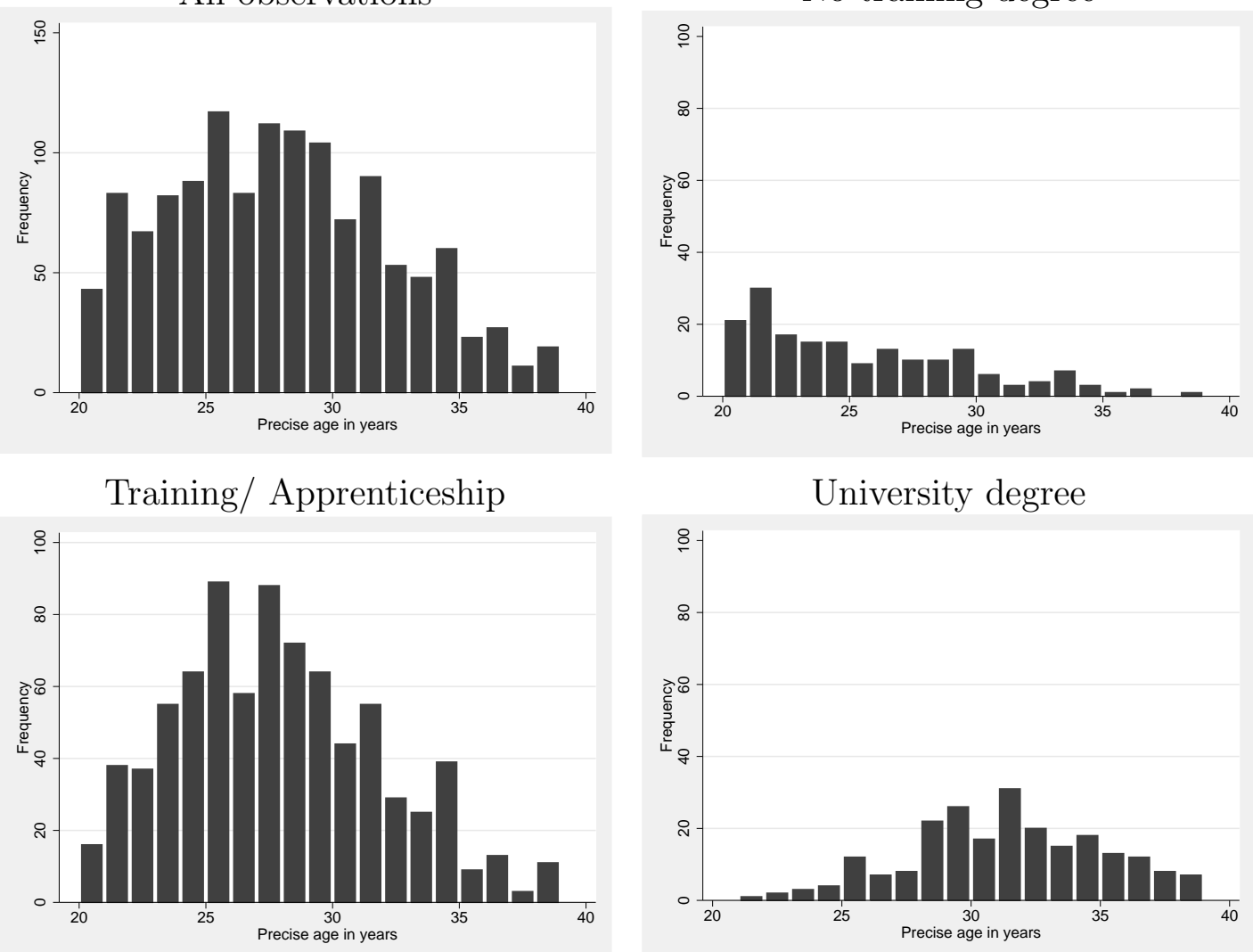

University degree

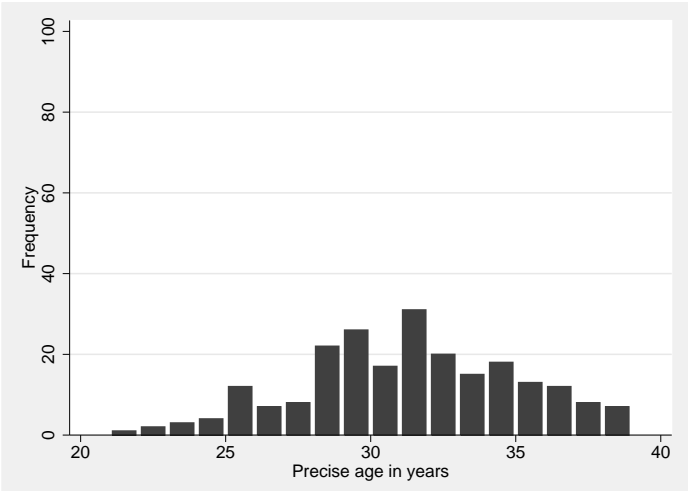


Figure 3: Distributions of propensity score

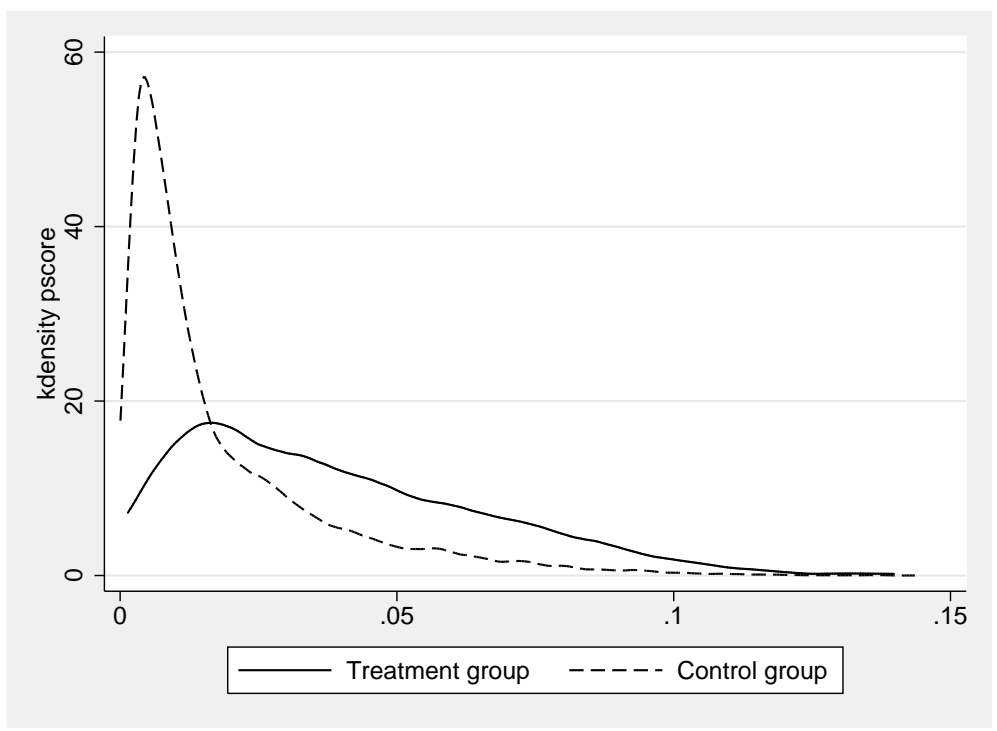

Figure 4: Completed training degrees one year before birth, by age at birth

University degree

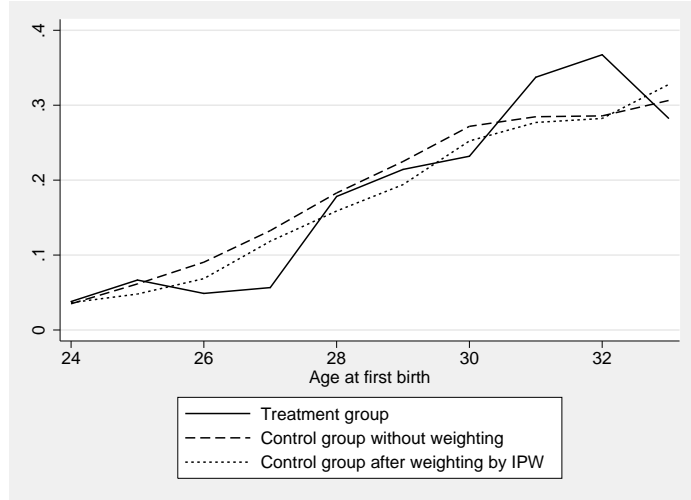

No training degree

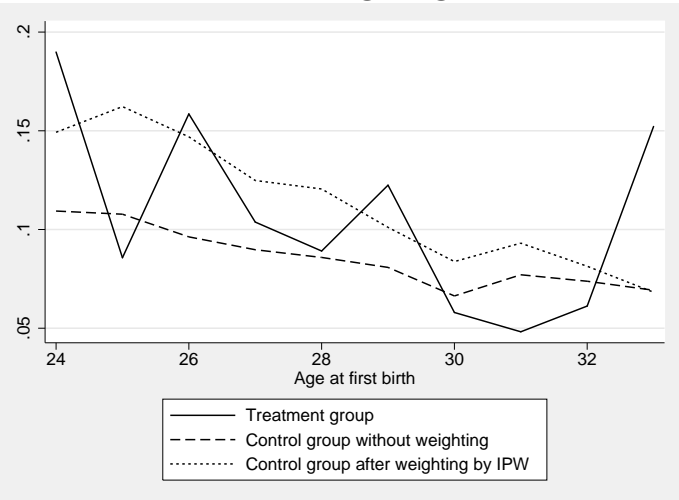

Training/ Apprenticeship

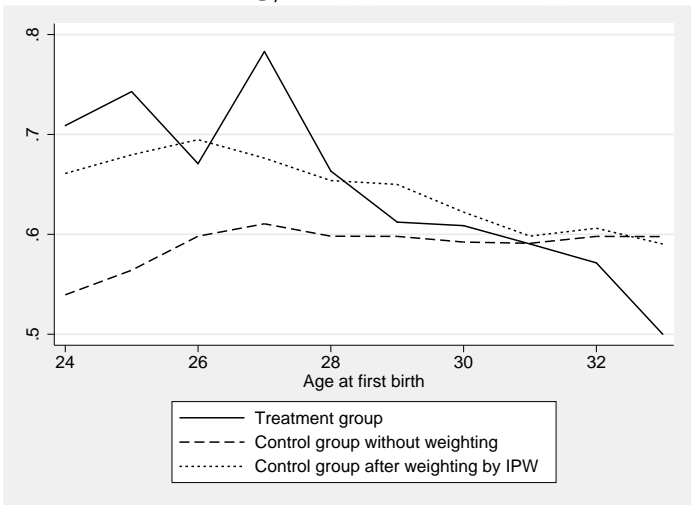

In education (or missing)

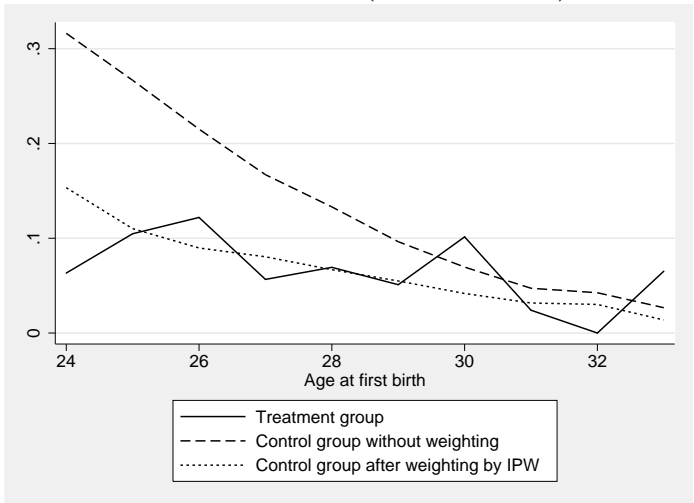


Figure 5: Partnership one year before birth, by age at birth

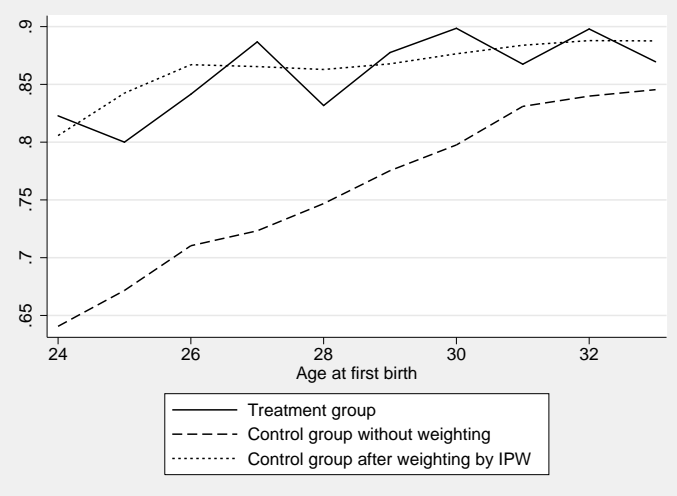

Figure 6: Employment one year before birth, by age at birth

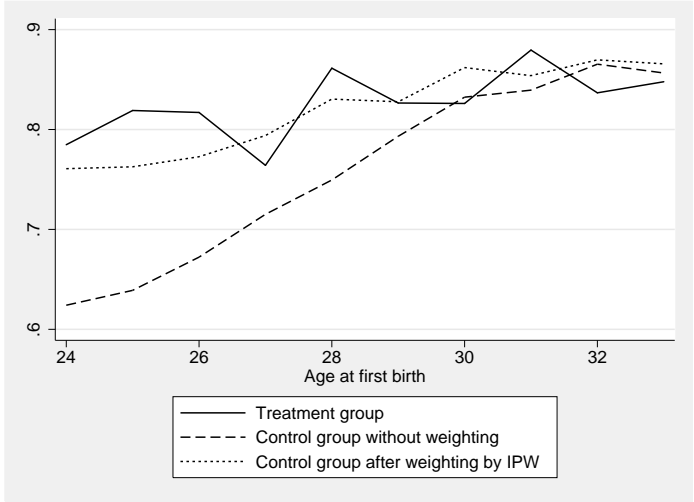

Figure 7: Employment rates before and after reweighting

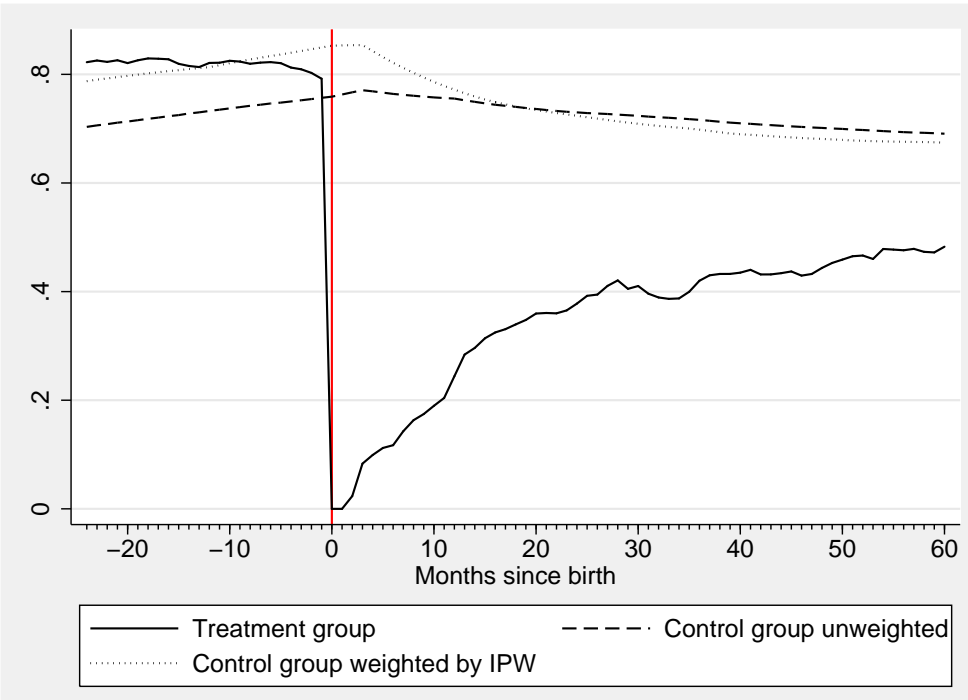

Figure 8: Employment rates by working time

Full time employment rates

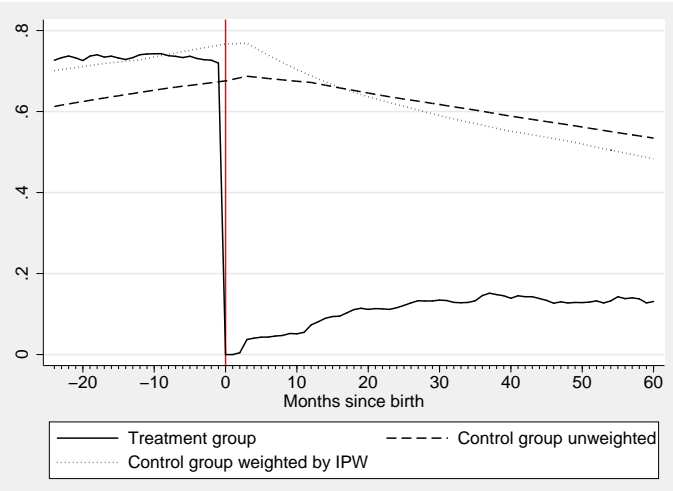

Part time employment rates

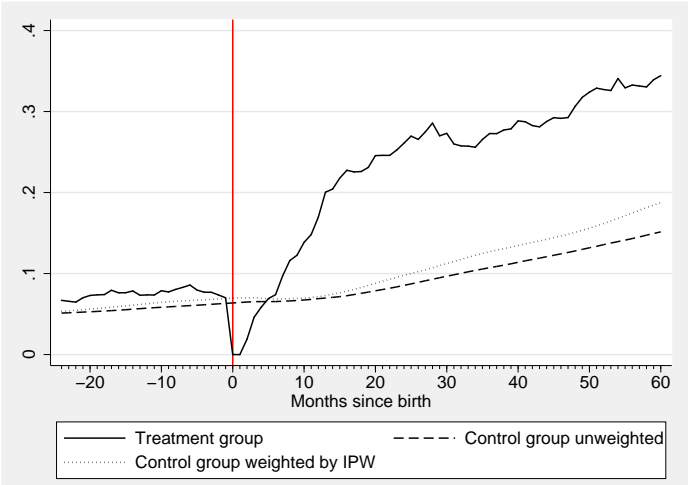


Figure 9: Childbirth rates for treatment and control group (IPW-weighted)

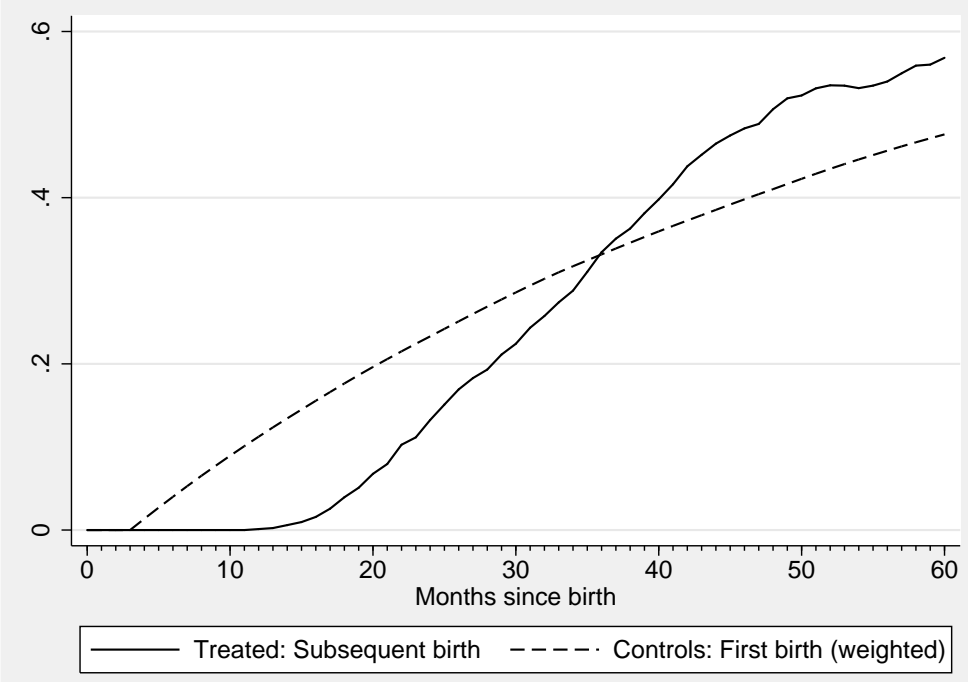

Figure 10: Average Treatment Effect on the Treated (ATT)

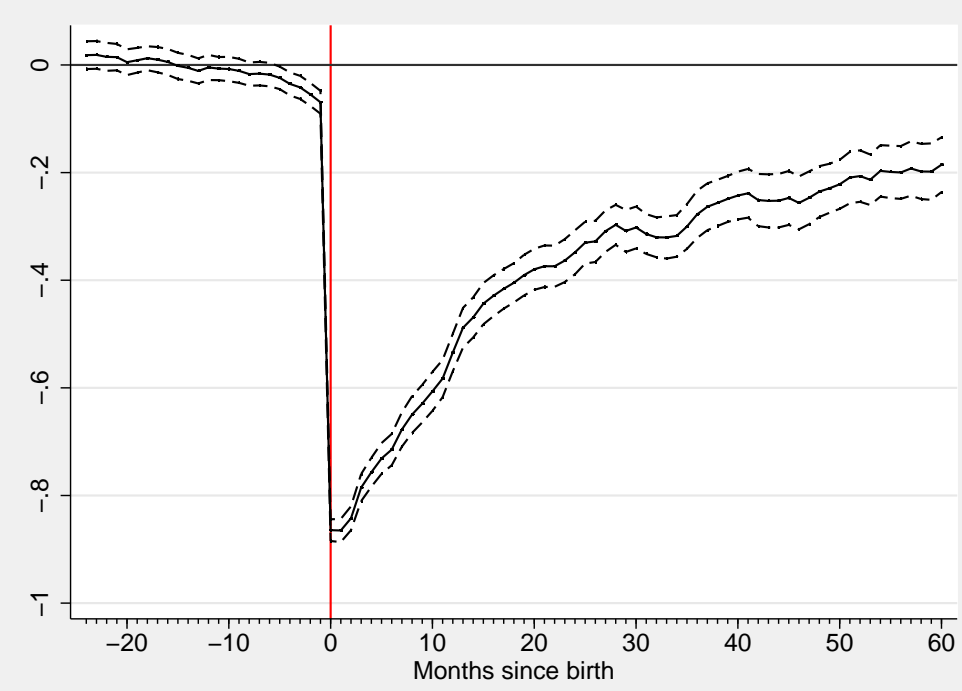


Figure 11: ATTs for different age groups

ATT age 24 and 25

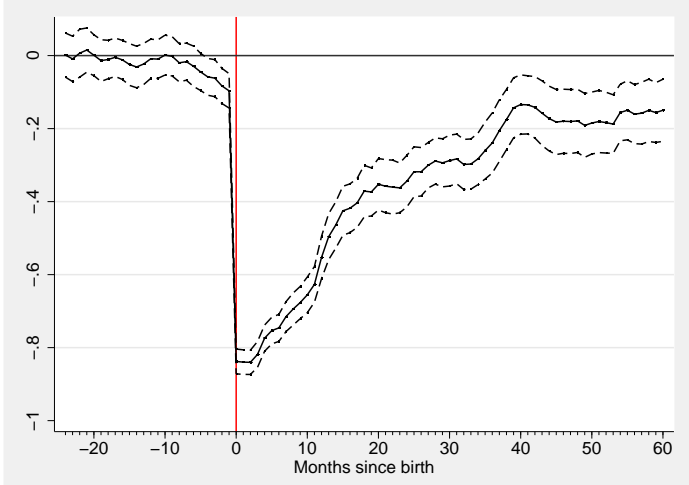

ATT age 28 and 29

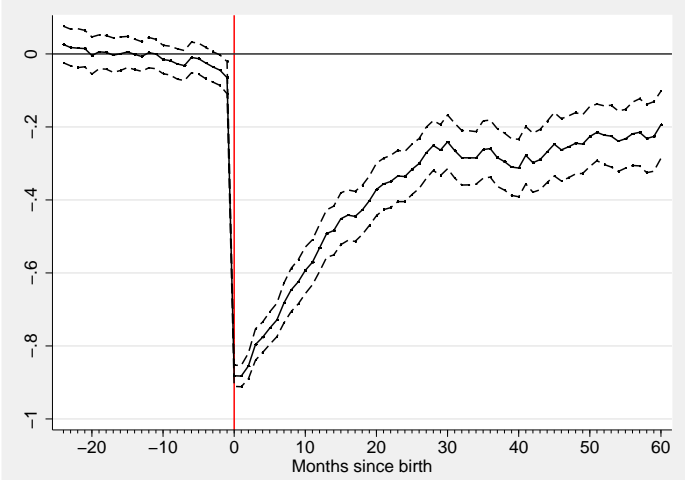

ATT age 26 and 27

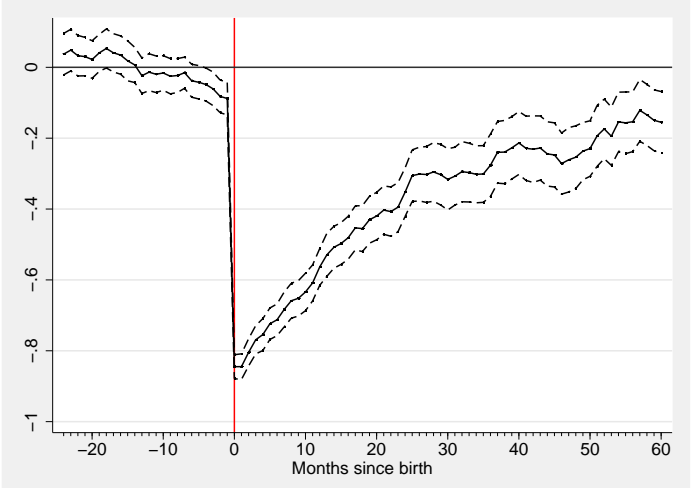

ATT age 30 and 31

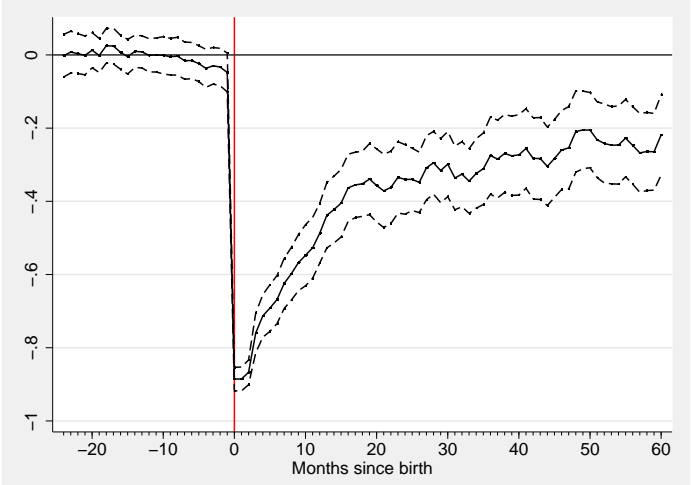

ATT age 32 and 33

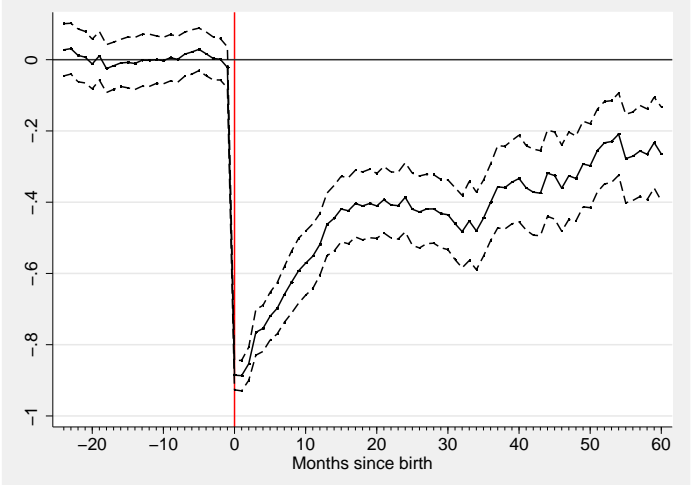


Figure 12: Childbirth rates by age

Treatment group: Second births

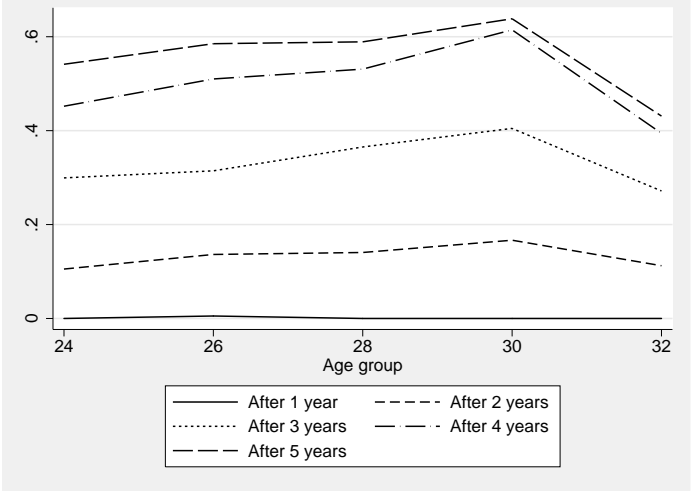

Control group: First births, IPWweighted

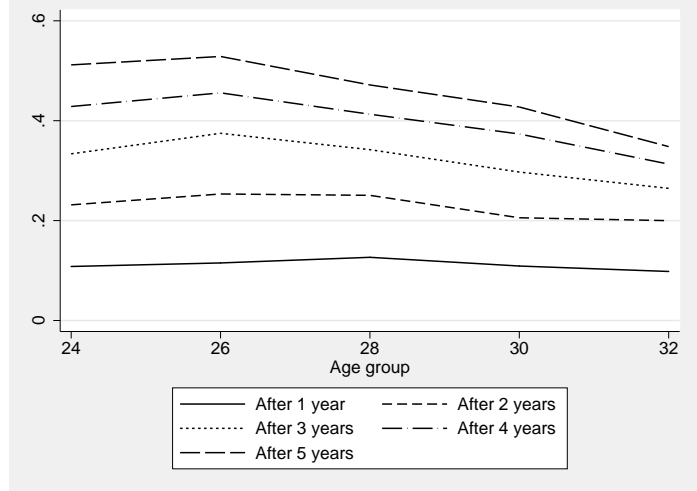

Figure 13: ATTs for different educational levels

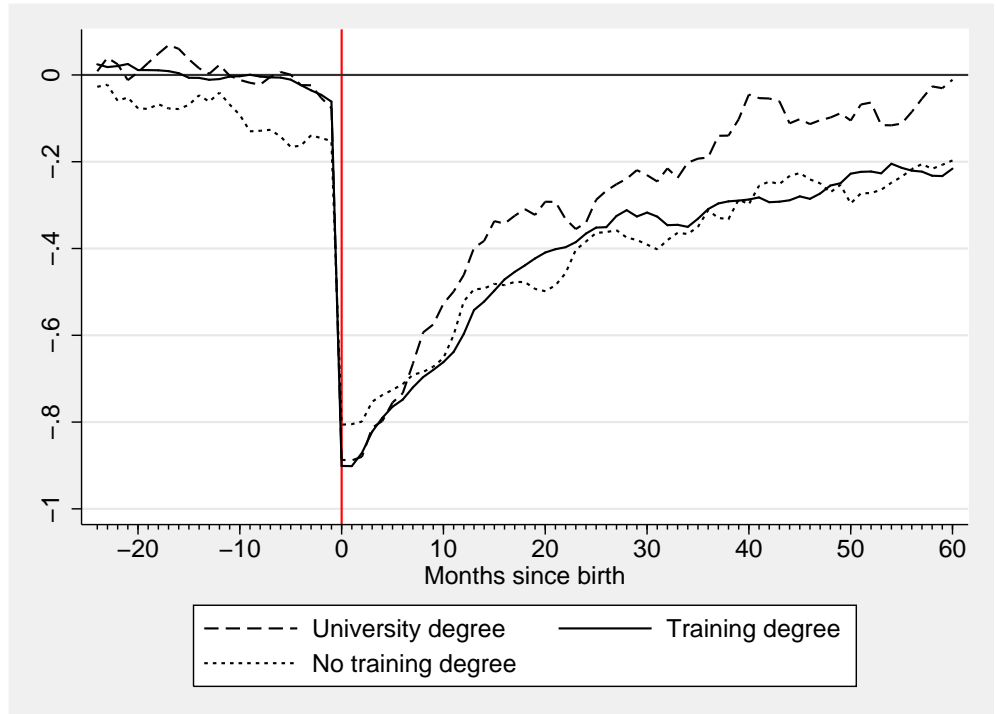


Figure 14: ATTs for different educational levels

Effect for mothers without training degree

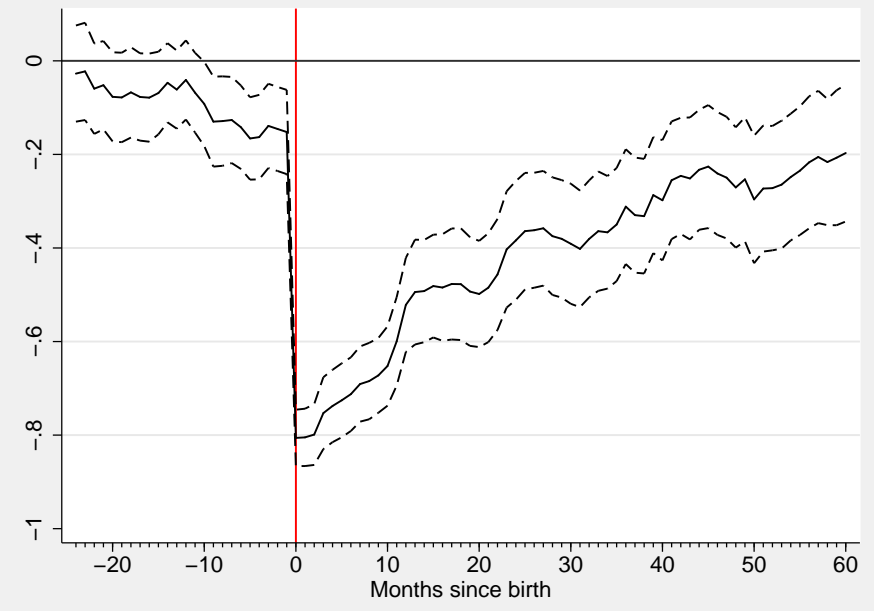

Effect for mothers with training degree

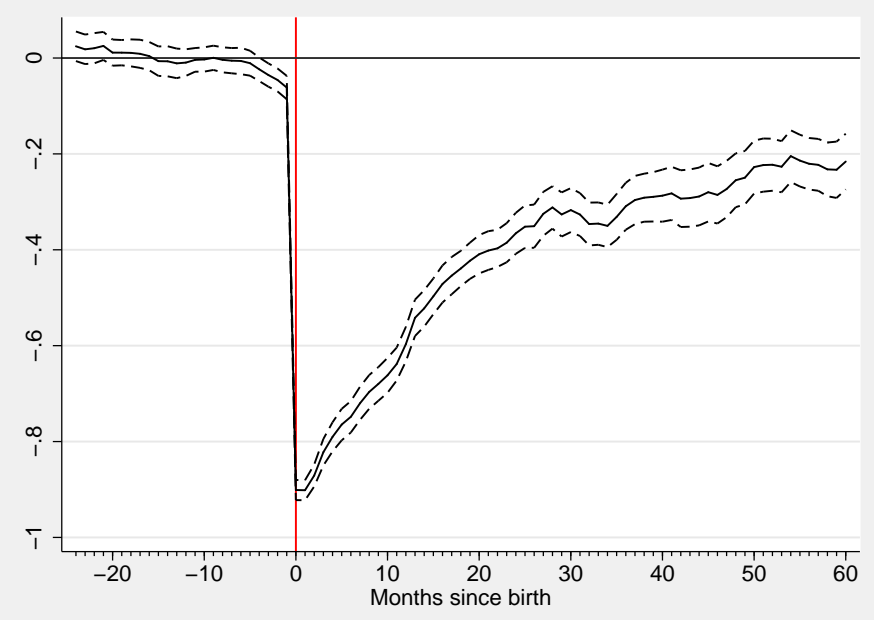

Effect for mothers with university degree

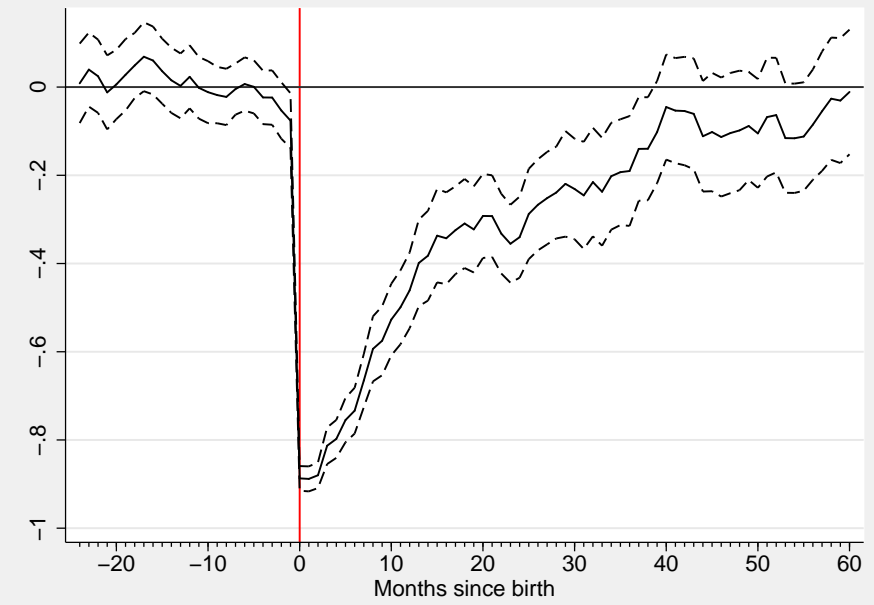


Figure 15: ATTs for age and education groups

\section{ATT age 28 and 30}

Training/ apprenticeship degree

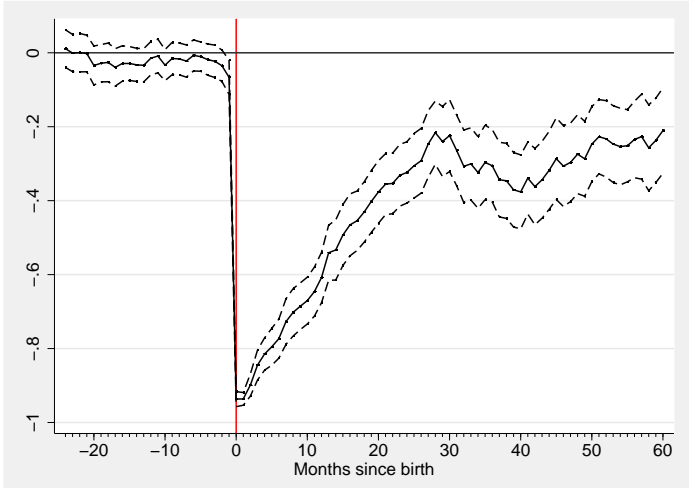

University degree

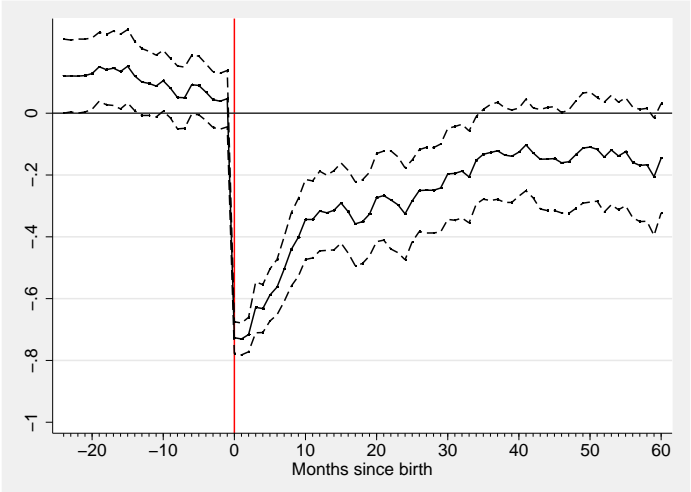

ATT age 30 and 31
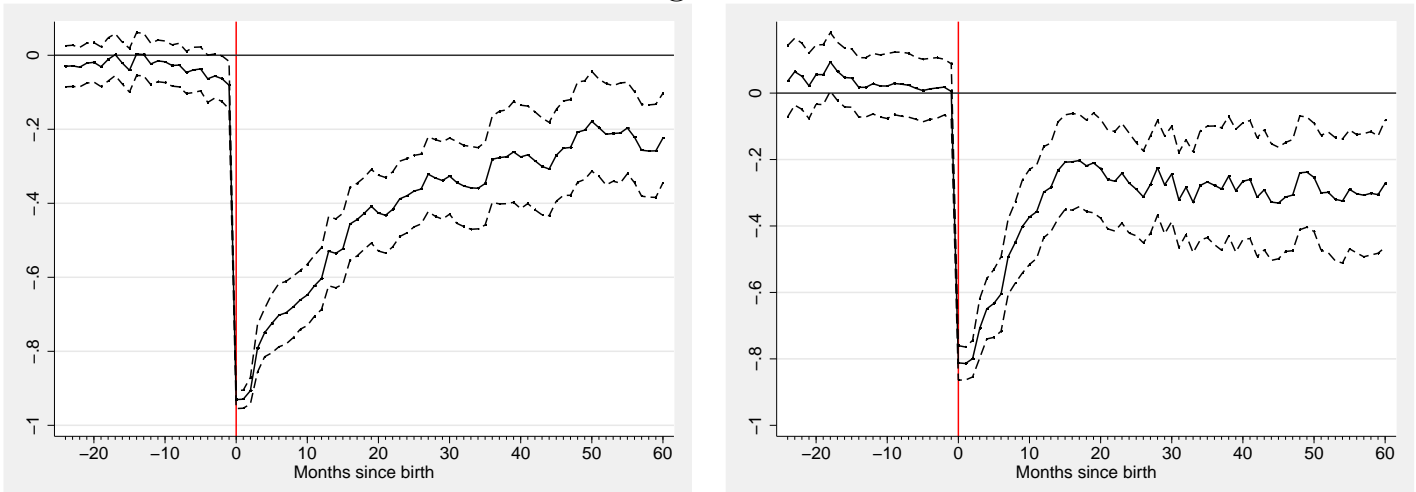

ATT age 32 and 33

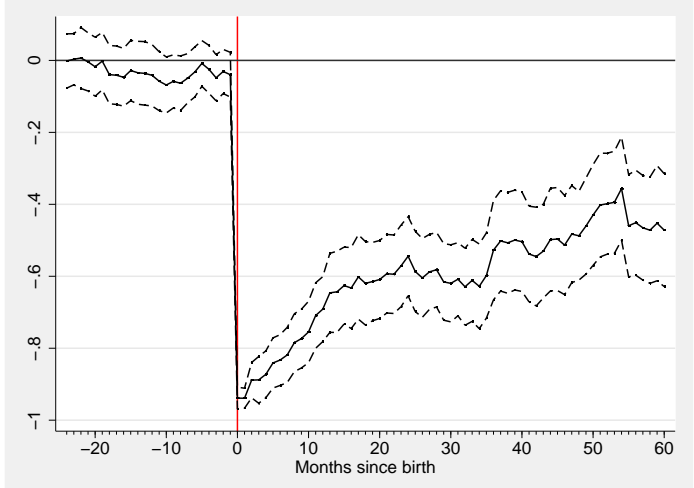


Figure 16: Linear time trend in ATT

Year specific coefficients of time trend ATT for childbirth in 1993 / 2003
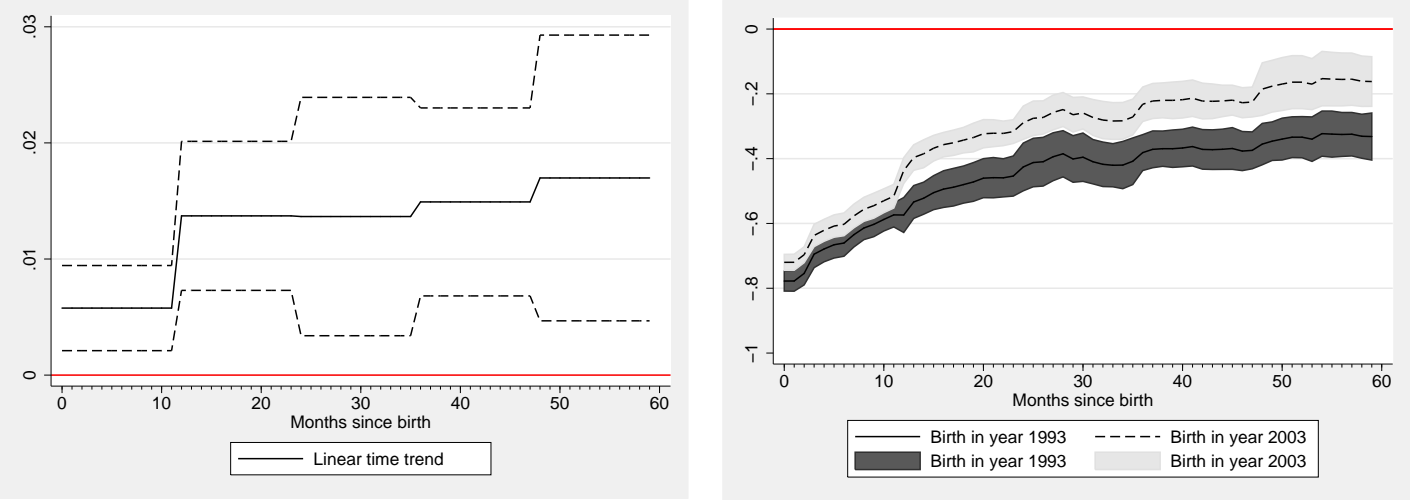

Figure 17: Sensitivity Analysis: No reweighting

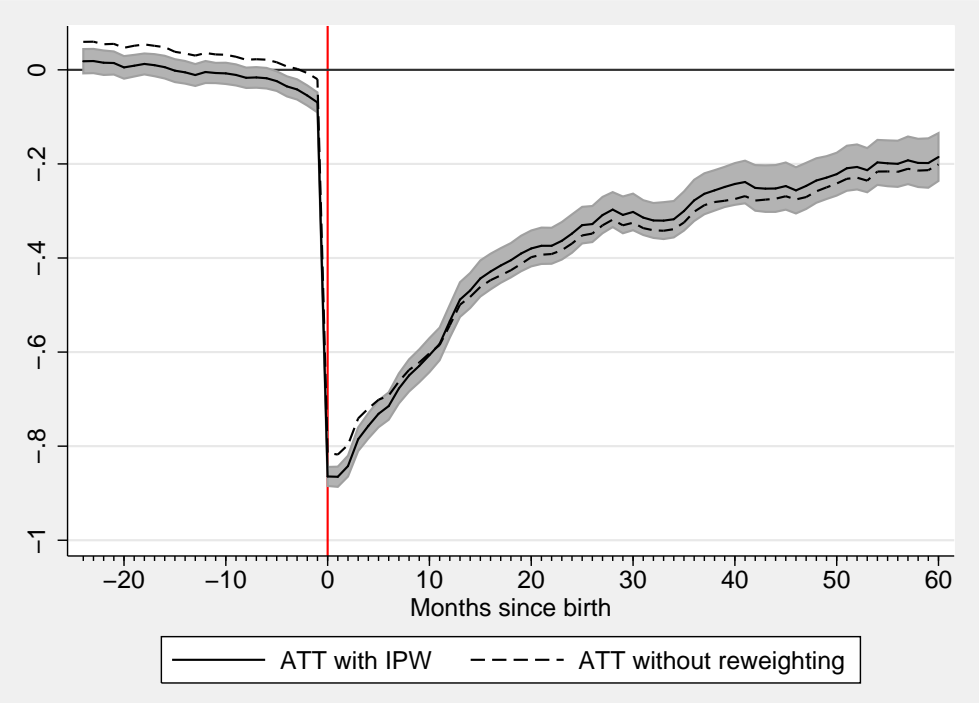


Figure 18: Sensitivity Analysis: Drop 3-months-window

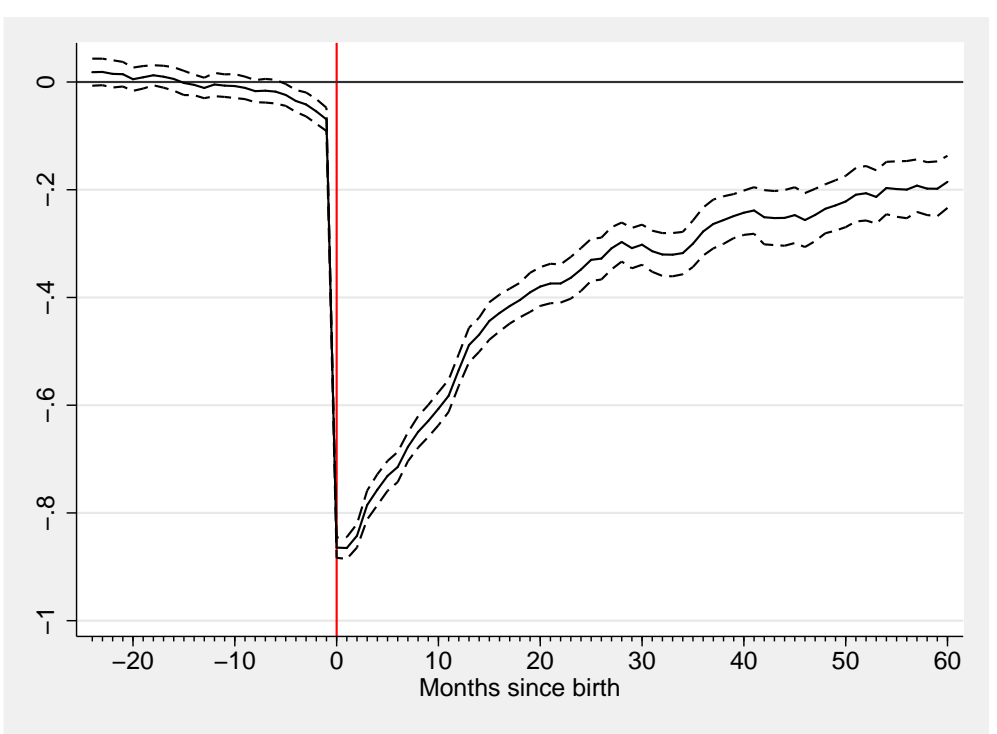

Figure 19: Sensitivity Analysis: Varying control group selection

Control group: Have first child soon

(i.e. within two years)

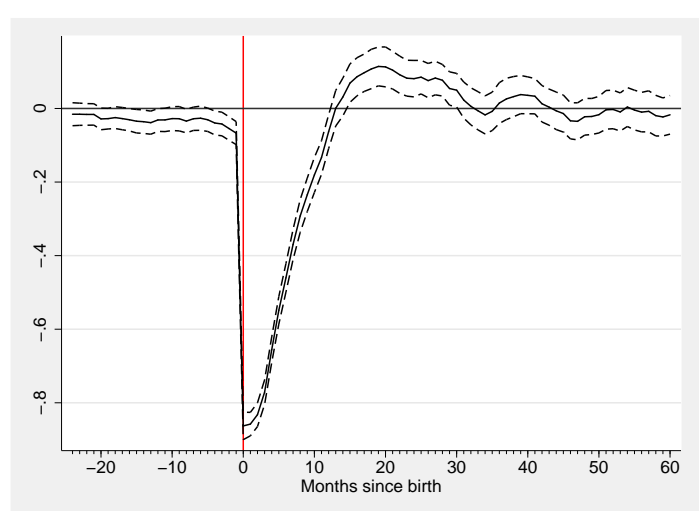

Figure 20: Sensitivity Analysis

No second births in treatment group

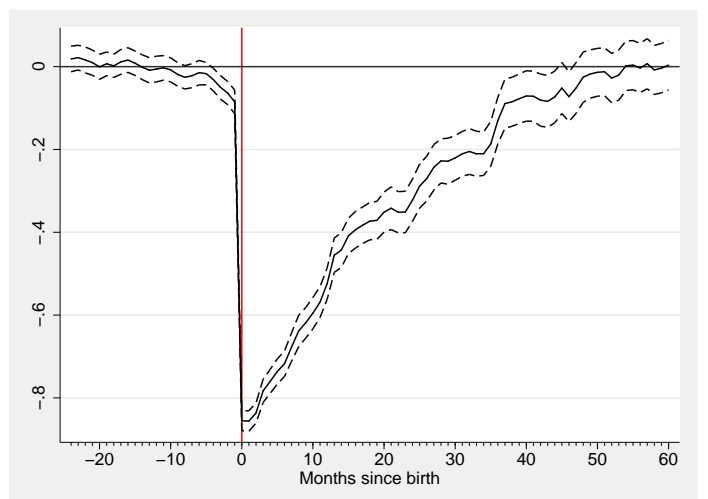

Control group: Have first child late or never (i.e. after 5 years or more)

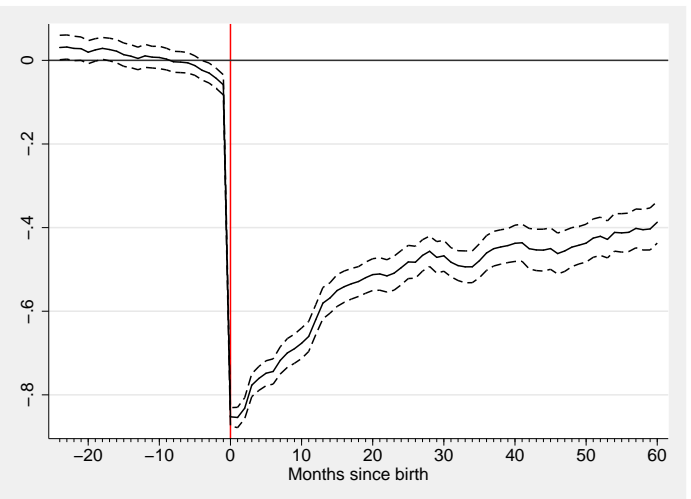

Figure 21: Sensitivity Analysis

Only balanced panel

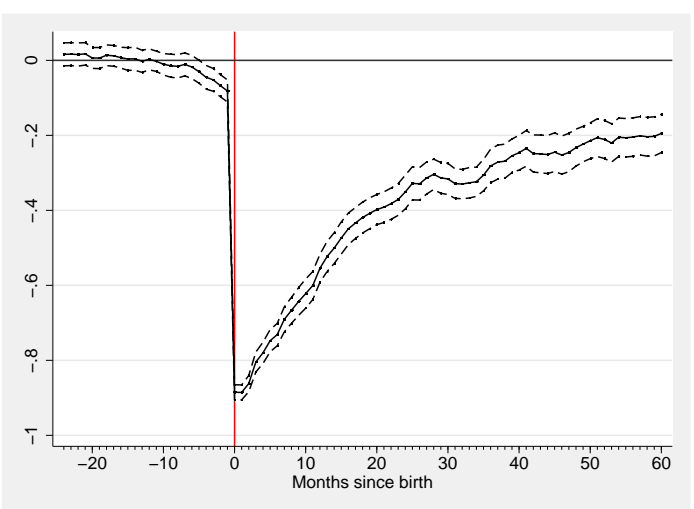

